NBER WORKING PAPER SERIES

\title{
PATIENT RESPONSES TO INCENTIVES IN CONSUMER-DIRECTED HEALTH PLANS: EVIDENCE FROM PHARMACEUTICALS
}

\author{
Peter J. Huckfeldt \\ Amelia Haviland \\ Ateev Mehrotra \\ Zachary Wagner \\ Neeraj Sood \\ Working Paper 20927 \\ http://www.nber.org/papers/w20927 \\ NATIONAL BUREAU OF ECONOMIC RESEARCH \\ 1050 Massachusetts Avenue \\ Cambridge, MA 02138 \\ February 2015
}

This study was funded in part by a grant from the National Institute of Aging (NIA) and the NIH Common Fund for Health Economics (Grant R01-AG043850) and a grant from the California Health Care Foundation. The authors thank Teague Ruder for programming support and seminar participants at the American Society of Health Economics biennial meetings, the International Health Economics Association annual meetings, RAND, the University of Southern California, the University of Minnesota, Vanderbilt University, Emory University, and McGill University. The views expressed herein are those of the authors and do not necessarily reflect the views of the National Bureau of Economic Research.

NBER working papers are circulated for discussion and comment purposes. They have not been peerreviewed or been subject to the review by the NBER Board of Directors that accompanies official NBER publications.

(C) 2015 by Peter J. Huckfeldt, Amelia Haviland, Ateev Mehrotra, Zachary Wagner, and Neeraj Sood. All rights reserved. Short sections of text, not to exceed two paragraphs, may be quoted without explicit permission provided that full credit, including $\mathbb{C}$ notice, is given to the source. 
Patient Responses to Incentives in Consumer-directed Health Plans: Evidence from Pharmaceuticals Peter J. Huckfeldt, Amelia Haviland, Ateev Mehrotra, Zachary Wagner, and Neeraj Sood NBER Working Paper No. 20927

February 2015

JEL No. I1,I13

\begin{abstract}
$\underline{\text { ABSTRACT }}$
Prior studies suggest that consumer-directed health plans (CDHPs) -characterized by high deductibles and health care accounts- reduce health costs, but there is concern that enrollees indiscriminately reduce use of low-value services (e.g., unnecessary emergency department use) and high-value services (e.g., preventive care). We investigate how CDHP enrollees change use of pharmaceuticals for chronic diseases. We compare two large firms where nearly all employees were switched to CDHPs to firms with conventional health insurance plans. In the first firm's CDHP, pharmaceuticals were subject to the deductible, while in the second firm pharmaceuticals were exempt. Employees in the first firm shifted the timing of drug purchases to periods with lower cost sharing and were more likely to use lower-cost drugs, but the largest effect of the CDHP was to reduce utilization. Employees in the second firm also reduced utilization, but did not shift the timing or use of low cost drugs.
\end{abstract}

Peter J. Huckfeldt

Division of Health Policy and Management

School of Public Health

University of Minnesota

420 Delaware Street Southeast Mmc88

Minneapolis, MN 55455

huckfeld@umn.edu

Amelia Haviland

Carnegie Mellon University

Pittsburgh, PA

amelia@andrew.cmu.edu

Ateev Mehrotra

Harvard Medical School

180 Longwood Ave. Boston, MA 02115

mehrotra@rand.org
Zachary Wagner

University of California Berkeley

zwagner@berkeley.edu

Neeraj Sood

Schaeffer Center for Health Policy and Economics

3335 S. Figueroa Street, Unit A

Los Angeles, CA 90089-7273

and NBER

nsood@healthpolicy.usc.edu 


\section{Introduction}

It remains unclear what has driven the recent drop in the growth rate of health care costs. One proposed explanation is increased cost sharing for workers with employer sponsored health plans (Cutler and Sahni 2013; Haviland et al. 2012). The percentage of workers with health insurance coverage enrolled in Consumer-Directed Health Plans (CDHPs), defined here by an annual single deductible of $\$ 1,000$ or more and a tax-advantaged personal medical account, has increased from 4 percent in 2006 to 20 percent in 2013 (KFF and HRET 2013) ${ }^{1}$. The intent of CDHPs is to make consumers more conscious of the price and quality of services and thereby use fewer "lower value" services (e.g., unnecessary emergency department visits), but have no impact or increase use of "higher value" services (e.g. preventive care or prescription drug use for chronic illnesses).

Prior research finds, with some exceptions, reductions in total costs in the years after initial enrollment in CDHPs or high deductible plans (e.g., Buntin et al. (2011), Lo Sasso et al (2010)). However, there is more disagreement on whether such reductions represent the intended response: price shopping for high value care and selective reduction of low-value care versus indiscriminate reductions in all health care. Bundorf (2012) comprehensively reviews the literature on CDHPs and high deductible plans and finds that utilization reductions are focused primarily in outpatient spending and pharmaceutical care (e.g., Lo Sasso et al. (2010), Parente, Feldman, and Chen (2008)). It is unclear, however, whether reductions in outpatient and drug spending are driven by reductions in needed or unnecessary care. The literature finds mixed evidence on use of preventive services exempt from the deductible (for example, Buntin et al. (2011) and Charlton et al. (2011) find reductions, while Wharam et al. (2008) do not). Recent

\footnotetext{
${ }^{1}$ IRS regulations setting the minimum deductible eligible for tax-advantaged personal medical account contributions has increased over time; it was $\$ 1,000$ for a single/ $\$ 2,000$ for a family in 2004 and increased to $\$ 1,250 / \$ 2,500$ by 2013 .
} 
research on prescription drugs finds evidence of reduced adherence among enrollees with chronic diseases after a firm adopts a CDHP, but does not consider the full range of enrollee responses such as generic use and shifting the timing of purchase (Fronstin, Sepulveda, and Robebuck 2013).

We build on this prior literature by investigating how CDHPs influence the use of prescription drugs for chronic diseases. Pharmaceuticals provide a useful context for testing responses to CDHPs because they are used frequently, whether a drug is "generic" provides a clear signal of cost (often absent for other health care services), and finally, pharmaceutical costs are both non-trivial but also do not immediately surpass the deductible. As a result, beneficiaries using pharmaceutical therapies for a chronic condition will repeatedly face higher out-of-pocket prices, providing greater opportunity to gain familiarity with benefit structure and change behavior. In addition, adherence to drugs treating chronic illnesses is a critical public health issue.

The first contribution of this paper to the literature is using an identification strategy that plausibly estimates the causal impact of CDHP adoption. One challenge in estimating the effects of CDHP enrollment on prescription drug use is that employees who elect to enroll in a CDHP may differ from other employees in observed and unobserved characteristics that may also influence health care utilization. We exploit a natural experiment and compare three groups: (1) employees in a large firm that shifted all health coverage to CDHPs in 2005 and where pharmaceuticals were subject to the deductible (i.e., beneficiaries paid the total cost of pharmaceuticals up through the deductible); (2) employees in another large firm that shifted all health coverage to CDHPs in 2005, but where pharmaceuticals were exempt from the deductible and thus beneficiaries just paid standard copayment rates; and (3) employees in 19 other large 
firms that only offered traditional plans throughout the study period. The inclusion of the second firm with a pharmaceutical exemption allows us to investigate whether employees change utilization of pharmaceuticals even without a change in pharmaceutical cost structure. Such a change might be driven by misunderstanding of benefit structure or increased cost sharing for physician visits. Because the CDHP firms shifted virtually all employees to CDHPs, we are able to mitigate selection bias from take-up. In addition, because we compare enrollees before and after the shift to CDHPs, we can control for all time-invariant beneficiary characteristics (at the firm level) that may influence health care utilization.

The second contribution of this paper is to examine a comprehensive set of potential responses to the incentives present in CDHPs, to understand whether enrollees demonstrate forward-looking behavior versus responses with potentially adverse health impacts. An intended and forward-looking response to CDHP benefit structure could include switching to drugs that are cheaper but equally effective; a key example of this could include shifting to generic drugs. Shifting to a less effective generic drug, however, could have adverse long-term impacts. We compare responses among health plan enrollees using drug classes treating high cholesterol, hypertension, and diabetes, where the relative efficacy of generic or low cost alternatives varies across condition categories. An unintended but forward-looking response may be to shift the timing of drug purchase to the periods with low cost sharing. Specifically, consumers could stock up on drugs prior to the switch to the CDHP or upon reaching the deductible. We investigate each of these timing responses. An additional unintended and non-forward looking response with potentially adverse health impacts is reducing medication adherence, which may reduce current out-of-pocket spending, but increase later health care costs from complications of chronic diseases. 
The third contribution of this paper is to quantify the relative magnitudes of each behavioral response. Specifically, we compare total and out-of-pocket spending on prescription drugs with CDHP cost sharing and post-CDHP observed behavior relative to CDHP cost sharing and pre-CDHP behavior (i.e., no behavior change) along each response margin: reduced drug utilization, the timing of drug purchases, and use of generic or lower-cost drugs.

Overall, we find evidence that employees in the CDHP with pharmaceuticals subject to the deductible use more low cost drugs and shift the timing of drug purchases to periods with lower cost sharing. The majority of the response, however, is to reduce overall drug utilization. These results imply that enrollees possess some awareness of benefit design and availability of low cost drugs, but also suggest that enrollees either discount or are not cognizant of the adverse consequences of poor adherence. Employees in the CDHP with pharmaceuticals exempt from the deductible also exhibit decreased utilization relative to firms with conventional coverage. The presence of a utilization response may suggest a lack of understanding of plan design or reflect secondary effects where increased cost sharing leads to fewer physician visits where drugs are prescribed. The persistence of the response into the second year of the plan (presumably a sufficient time period for enrollees to understand plan design) may suggest this response is due to cost sharing for physician visits.

The paper proceeds as follows. In Section 2, we describe the firms and health plans in the study and potential behavioral responses to CDHP incentives. In Sections 3 and 4, we describe our empirical approach and data. Section 5 describes results, and Section 6 concludes. 


\section{Study framework}

\subsection{Firms and health plans in study}

We examine the prescription drug utilization of employees in 2 treatment firms and 19 control firms, where the firms were chosen for the types of health plans offered over the sample period. Health plan characteristics over the sample period are displayed in Table 1.

\section{CDHP firm 1: prescription drugs subject to the deductible}

The first treatment firm, "CDHP firm 1" in the first panel of Table 1, offered a PPO plan in 2004 in which prescription drugs copayments fell into three tiers ( $\$ 10$ for generic drugs, \$20 for brand drugs on the formulary, and $\$ 35$ for non-formulary brand drugs, in each case for a 30 day supply) and none of the employees were enrolled in a CDHP (defined by a high deductible and health care account). In 2005, nearly all employees shifted to a CDHP with a single deductible of $\$ 1,000$, a family deductible of $\$ 2,000$, and employer-provided health reimbursement accounts (HRAs), in which employees received \$500 (for single policy holders) or $\$ 1,000$ (for families) tax-free each year to defray out-of-pocket health costs. Unspent funds in HRAs rollover across years, but enrollees lose the funds if they leave the employer. Prescription drugs were subject to the deductible (i.e., require 100 percent cost sharing before reaching the deductible) and required 20 percent coinsurance upon reaching the deductible. The percentage of employees enrolled in a high deductible plan (defined in this time period as a deductible of at least $\$ 1,000$ ) fell to 73 percent in 2006 , but the remainder enrolled in a plan with moderately high deductibles of $\$ 750$ for singles and $\$ 1,500$ for families (and we keep them in the sample).

\section{CDHP firm 2: prescription drugs exempt from the deductible}

The second treatment firm, displayed in the second panel of Table 1, also used tiered copayments for pharmaceuticals in 2004 and only three percent of employees were enrolled in a 
high deductible health plan and held a health reimbursement account. Starting in 2005, nearly all employees switched to high deductible plans usually paired with health reimbursement accounts, with a small percentage enrolling in health savings accounts (HSAs) (similar to HRAs but portable across employers). Employees chose between plans with a deductible of $\$ 1,000 / \$ 2,000$, $\$ 1,200 / \$ 2,400$, or $\$ 1,500 / \$ 3,000$ for single policyholders/families. In addition, the employer provided $\$ 400$ for single policyholders or $\$ 1,200$ for families in a HRA. In contrast to the first firm, drugs were exempt from the deductible and employees continued to pay the same tiered copayments after the CDHP was implemented in 2005. Plan parameters were similar in 2006, although the tiered drug copayments were slightly higher in nominal terms.

\section{Firms with traditional health plans never offering CDHPs}

We selected 19 large firms that only offered traditional health plans during the 2004-2006 plan years to serve as comparison firms; the data and selection process are described in more detail in Section 5. The third panel of Table 1 summarizes the plan structure for the comparison firms. Most of the firms used copayments for prescriptions drugs (rather than coinsurance); among such firms, median copayments for a 30-day supply indicate a tiered copayment structure with overall levels of cost sharing below that in the CDHP firms in the pre-period. By construction, virtually none of the health plans in the control firms included high deductibles ( $\$ 1,000$ for single policyholders) or personal medical accounts ${ }^{2}$.

\subsection{Potential responses to CDHP enrollment, by drug class}

We examine three margins by which new enrollees in CDHPs may change utilization of health care. First, enrollees may shift the timing of health care utilization to periods of lower cost sharing. One example is the period immediately prior to the switch from typical coverage with

\footnotetext{
2 Among enrollees in the control firms, 23 individuals had a high deductible plan (6 in 2005 and 17 in 2006) and 38 had a health savings account (without a high deductible plan) in 2006. These cases are rare and anomalous, so we kept these firms and did not drop the enrollees from the sample.
} 
no or a low deductible to a CDHP. Another period is after the enrollee reaches the yearly deductible (if they do so). Specifically, if there is uncertainty about reaching the deductible in the next year, enrollees may reduce total out-of-pocket spending by "stocking up" on health care after reaching the deductible. Second, new enrollees may respond to CDHP incentives by reducing their use of drugs. Third, enrollees may switch to cheaper drugs, such as generic drugs or lower cost drug classes.

We examine changes in utilization of prescription drugs, focusing on classes providing prevention of disease and disease complications among patients with three conditions: (1) high cholesterol, (2) hypertension, and (3) type 2 diabetes. The full list of drugs is given in Appendix Table A.10. There are a number of advantages for considering utilization of drugs used for longterm chronic conditions to identify enrollee responses to CDHP incentives. Because enrollees fill their prescriptions repeatedly, there is an opportunity to learn the incentive structure of CDHPs through repeated encounters with the plan design. Pharmaceuticals also contain clear cost signals through brand name versus generic status, facilitating price shopping. Pharmaceuticals can be considered a "durable" good in the medium term, in that consumers are able to purchase drugs a number of months prior to taking them. Finally, we included drugs in the sample that have been found cost-effective based on conventional thresholds, supporting the assertion that discontinuation of therapy is suboptimal behavior. The relationship between cost and quality across specific drugs within a health condition category, however, differs across the three categories, as we describe below. We use these differences to contrast drug classes where generic or low cost drugs are more or less effective relative to brand name or higher cost drugs. 


\section{Statins}

Statins are cholesterol-lowering drugs that have been shown to be a cost-effective means of preventing cardiovascular disease for patients with a range of cardiovascular risk factors (Ward et al. 2007). During the first years of our sample period (2004 and 2005), the only generic statin available was lovastatin. Lovastatin is less effective than other statins, especially compared to simvastatin and atorvastatin (Lipitor) (Jones et al. 1998). In 2006, generic simvastatin became available and studying the take-up of generic simvastatin among CDHP members provides an additional natural experiment.

In the analysis of statin utilization, we examine responses to CDHP incentives in the timing of statin purchases (timing margin), overall statin use (utilization margin), and the use of generic versus brand name statins (low cost drug margin). Because there is a positive relationship between cost and quality (i.e., brand name statins were better quality than generic statins, particularly in 2005), we may expect less of a response along the low cost drug margin for statins compared to the other drug categories for employees in CDHP firm 1 (where prescription drugs are subject to the deductible).

\section{Antihypertensive drugs}

In this drug category, we focus on two drug classes. Angiotensin-Converting Enzyme (ACE) inhibitors and Angiotensin II Receptor Blockers (ARBs) were recommended second-line drugs during the study period treating hypertension when first-line drugs alone are ineffective (which is often the case) (Chobanian et al. 2003) ${ }^{3}$. ARBs are a newer drug class that were on patent during the sample period and thus were significantly more expensive than ACE inhibitors which were mostly generic during the sample period; however, ACE inhibitors have been shown

\footnotetext{
${ }^{3}$ In the latest guidelines these drugs are first line.
} 
equally effective as $\mathrm{ARBs}^{4}$ (Matchar et al. 2008). We investigate responses to CDHP incentives in the timing of antihypertensive purchase (timing margin), overall use of antihypertensive drugs (utilization margin), and the use of ACE inhibitors relative to ARBs (low cost drug margin). In contrast to statins, there is no relationship between cost and quality between ARBs and ACE inhibitors as they are equally effective. As a result, we may expect to see a larger response for antihypertensive drugs along the low cost drug margin compared to statins.

\section{Drugs for type 2 diabetes}

We investigate three types of drugs that improve blood sugar control for patients with type 2 diabetes: sulfonylureas, biguanides (metformin), and thiazolidinediones (also known as glitazones). Sulfonylureas and metformin are commonly used first-line pharmaceutical treatments, have been shown to be cost-effective (e.g., Clark et al. (2001)) and were off patent and inexpensive during the sample period. In contrast, glitazones were patented and more expensive and have no clear benefit over sulfonylureas and metformin as an additional agent or taken independently (Bolen et al. 2007). Moreover, prior to the sample period, glitazone use was linked to increased risk of heart failure (Delea et al. 2003) and later rosiglitazone was found to be associated with a higher risk of other adverse cardiovascular outcomes (Nissen and Wolski 2007). Therefore, in contrast to statins and anti-hypertensive drugs, we expect greater a response along the low cost drug margin relative to antihypertensives and statins because (1) use of metformin and sulfonylureas alone is similarly effective as when paired with glitazones (or taking glitazones alone), and (2) the more expensive glitazones have a higher risk of cardiovascular complications.

In the analysis of type 2 diabetes drugs, we investigate responses to CDHP incentives in

\footnotetext{
${ }^{4}$ The only clear indication for ARBs is in the $\sim 10$ percent of patients who take ACE inhibitors and develop a cough.
} 
shifts in the timing of purchase (the timing margin), the overall use of type 2 diabetes drugs (utilization margin), and use of metformin and sulfonylureas alone versus use of glitazones (low cost drug margin).

\section{Potential responses in CDHP firm 2 (pharmaceuticals exempt from the deductible)}

Employees in CDHP firm 2, where pharmaceuticals are exempt from the deductible, face no change in prescription drug cost sharing, which by itself could imply little effect of CDHP adoption on prescription drug use. CDHP firm 2 employees do pay higher out-of-pocket costs for other services, however, including physician visits. If employees reduce physician visits, they may be less likely to obtain prescriptions or receive counseling from physicians to adhere to medications and thus reduce utilization. Alternatively, if employees in CDHP firm 2 do not understand the structure of benefit design, they may behave as though prescription drugs were subject to the deductible. While it is difficult to distinguish between these two types of responses, the misunderstanding of benefit design may diminish over time, while reductions in access through higher cost sharing for physician visits may persist. In addition, we may expect to see stronger responses along the utilization or timing margins relative to the low cost drug margin if responses are driven by higher cost sharing for physician visits.

\section{Empirical approach}

In this section, we describe our research design, our approach for performing inference, and finally we describe a decomposition exercise that calculates the relative magnitudes of different response margins. 


\subsection{Research design}

A key challenge in estimating the effects of CDHPs is that enrollment is not randomly assigned. As a result, individuals that elect to enroll in CDHPs may differ from traditional plan enrollees in observable and unobserved ways. We exploit a unique natural experiment of two large firms shifting nearly all employees to CDHPs in 2005. We employ a differences-indifferences approach, comparing changes in outcomes from 2004 to 2005 and 2006 among employees in the firms shifting to CDHPs relative to employees in 19 firms not adopting CDHPs. We focus on employees and dependents using one of the drugs in the three categories described above in 2004 that were continuously enrolled in health plans in 2004 and 2005 for the one-year sample or 2004 through 2006 for the second-year sample. Because we examine a constant cohort of enrollees, we estimate regressions at the firm-month level, estimating an initial regression specification such as that in equation (1),

$$
y_{f t}=\alpha+\delta_{f}+\beta_{t}+\theta^{C D H P}\left(\text { Year } 2005_{t} \times C D H P_{f}\right)+u_{f t}
$$

where $y$ is the average outcome for firm $f$ and month $t, \alpha$ is a constant, $\delta_{f}$ (where $\mathrm{f}=1,2, \ldots, 20$ ) is a vector of firm fixed effects, $\beta_{t}$ (where $\left.\mathrm{t}=1,2, . ., \mathrm{T}\right)$ are year-month fixed effects, and Year $2005_{t} \times C D H P_{f}$ is an indicator variable for being a CDHP firm times an indicator variable for the year 2005. $\theta^{C D H P}$ is the coefficient of interest and expresses the relative change in outcome in the CDHP firm post CDHP implementation relative to the change in outcome in firms only offering traditional plans. Equation (1) controls for general time trends (using the year-month fixed effects) and time-invariant firm characteristics (using the vector of firm fixed effects). We estimate equation (1) separately for CDHP firm 1 (where prescription drugs are subject to the deductible) and CDHP firm 2 (where prescription drugs are exempt from the deductible). For the two year sample, we estimate alternate versions of equation (1) that include 
an additional interaction term $\operatorname{Year}_{2006} \times C D H P_{f}$ to identify second year effects of the CDHP. We estimate an additional specification including bimonthly interactions to trace the dynamic effects of CDHP implementation over the course from the anticipation effects prior to the CDHP through the end of the first year of the CDHP.

Our identifying assumption is that the comparison firms exhibit the counterfactual utilization trend of each CDHP firm in the absence of CDHP adoption. We test this assumption by comparing the utilization trends of the CDHP firm and comparison firms prior to CDHP adoption.

\subsection{Inference}

Because the source of variation is at the firm level and we are separately investigating the two firms implementing CDHPs, each estimation is effectively a case study because there is only one treated unit for each analysis. Conventional approaches to inference, for example using cluster-robust standard errors, assume a larger number of treated units, and thus are likely to provide incorrect standard errors (Conley and Taber 2011). Instead, we perform inference using a permutation test, for example, as applied recently by Buchmueller et al. (2011). We perform the following process separately for each CDHP firm. First, we estimate the main specification with the CDHP firm assigned the "treatment" in equation (1). Next, we estimate equation (1) 19 more times, sequentially assigning each control firm "treatment" status and assigning the CDHP firm "control" status. We then rank $\theta^{C D H P}$ relative to the 19 placebo $\theta$ s and reject the null hypothesis if the ranking is extreme. We use one-sided hypothesis tests in order to identify which "tail" leads to rejection of the null hypothesis. For example, equation (2) displays the null hypothesis for use of generic drugs after CDHP implementation.

$H^{0}: \theta^{C D H P} \leq 0$ 
Thus, we would reject the null hypothesis for large values of $\theta^{C D H P}$, which would be expressed as a high ranking (e.g., 1 out of 20). The implied p-value is the distance of the ranking of $\theta^{C D H P}$ from the most extreme ranking opposite the null hypothesis, multiplied by 0.05 . For example, in the generic drug use example, if the estimate of $\theta^{C D H P}$ is ranked 1 out of 20 relative to the placebo $\theta \mathrm{s}$, then the p-value would be 0.05 , if 2 out of 20 then the p-value is 0.10 , and so on. We interpret the most extreme ranking as being statistically significant and the second most extreme ranking as being borderline statistically significant.

\subsection{Decomposition exercise}

The inferences about equation 1 parameters indicate the presence of different types of enrollee responses to CDHP incentives. They do not, however, indicate the relative magnitudes of these responses. We perform a post-estimation decomposition exercise that calculates the relative magnitudes of responses for CDHP firm 1 (prescription drugs exempt from the deductible) in 2005. Specifically, we separately examine the reductions in out-of-pocket and total expenditures generated by enrollees' responses to CDHP incentives, relative to what out-ofpocket and total expenditures would be with no change in behavior from 2004 but subject to 2005 CDHP cost sharing. Absent a change in behavior, out-of-pocket expenses would be higher in 2005 as enrollees faced higher cost sharing in 2005. In contrast, total expenditures could increase or decrease depending on changes in discounts or negotiated prices from 2004 to 2005. From this benchmark, we consider out-of-pocket and total savings each month associated with each estimated behavioral response: (1) shifting of purchase to periods with low cost sharing, (2) changes in overall drug use, (3) use of generics or low cost drugs (depending on the drug category) 
We consider two time periods: $t=0$ is the time period prior to CDHP in 2004 and $t=1$ is the time period after CDHP implementation in 2005. Average monthly expenditures in 2005 are indicated in equation 3 ,

$E^{1}=\left(1-s^{1}\right) g^{1} P_{g}^{1} Q^{1}+s^{1} g^{1} P_{g}^{0} Q^{1}+\left(1-s^{1}\right)\left(1-g^{1}\right) P_{b}^{1} Q^{1}+s^{1}\left(1-g^{1}\right) P_{b}^{0} Q^{1}$

where $E^{t}$ indicates monthly out-of-pocket or total expenditures in time period $t, g^{t}$ indicates the fraction of day supply that is generic in time period $t, P_{g}^{t}$ indicates the out-of-pocket or total price for generics per day supply in time period $t, P_{b}^{t}$ indicates the out-of-pocket or total price for branded drugs per day supply in time period $t, s^{1}$ represents the fraction of day supply when $t=1$ that comes from stocking drugs from time $t=0$, and $Q^{t}$ represents the average monthly days used in time period $t$.

The first term in equation 3 indicates expenditures per month for generic drugs purchased in period $t=1$, the second term indicates expenditures per month for generic drugs purchased in period $t=0$ but used in period $t=1$, the third term indicates expenditures per month for branded drugs purchased in period $t=1$, and the fourth term indicates expenditures per month for generic drugs purchased in period $t=0$ but used in period $t=1$.

\section{Changes in out-of-pocket and total expenditures from timing of purchase}

First, we examine out-of-pocket or total expenditures in 2005 with observed "stocking" behavior relative to expenditures without stocking behavior. Equation 4 displays the change in expenditures from stocking behavior.

$\Delta E^{s}=\left(E^{1} \mid s=s^{1}\right)-\left(E^{1} \mid s=0\right)=s^{1}\left[\left(P_{b}^{0}-P_{b}^{1}\right) Q^{1}\left(1-g^{1}\right)+\left(P_{g}^{0}-P_{g}^{1}\right) Q^{1} g^{1}\right]$

Savings will increase (or be more negative) with: the fraction of days stocked from the preCDHP period $\left(s^{l}\right)$, a larger increase in out-of-pocket spending for branded drugs between period 0 and period 1, a larger difference in out-of-pocket spending for generic drugs between periods 0 
and 1, and a larger monthly days used in period 1. In order to calculate equation (4), we again compute prices and utilization information using drug claims from the CDHP firm with prescription drugs subject to the deductible from 2005. We calculate $s^{l}$ using the difference in estimated regression coefficients from equation (1) between when the outcome is "days supply purchased" and "days used", as in equation (5):

$$
s^{1}=0.5\left(\theta^{\text {DaysUsed }}-\theta^{\text {DaysPurchased }}\right) / 30
$$

Each coefficient estimate gives the effect of the CDHP on days supply purchased or days used per month relative to the pre-CDHP period; the difference indicates the amount stocked times two ${ }^{5}$, which we divide by 30 to convert to a monthly proportion.

\section{Changes in total and out-of-pocket expenditures from days used}

We compute changes in expenditure from changes in overall utilization, holding generic use and stocking behavior to period $\mathrm{t}=1$ levels, as in equation (6).

$$
\begin{aligned}
\Delta E^{Q} & =\left(E^{1} \mid Q=Q^{1}\right)-\left(E^{1} \mid Q=Q^{0}\right) \\
& =\Delta Q\left[\left(1-s^{1}\right) g^{1} P_{g}^{1}+s^{1} g^{1} P_{g}^{0}+\left(1-s^{1}\right)\left(1-g^{1}\right) P_{b}^{1}+s^{1}\left(1-g^{1}\right) P_{b}^{0}\right]
\end{aligned}
$$

In this case, savings are accrued when out-of-pocket prices for generic or brand name drugs are higher in $\mathrm{t}=0$ or $\mathrm{t}=1$. To compute equation (6), we obtain $\Delta Q$ using the estimate of $\theta^{\text {Days Used }}$ from equation (1) and $s^{l}$ as described above; again, the other parameters are from the claims data for the main treatment firm in 2004 and 2005.

\footnotetext{
${ }^{5}$ Suppose CDHP enrollees stock $s$ days supply in the period prior to CDHP enrollment. Then the amount used is, DaysUsed $(\mathrm{t}=1)=$ DaysPurchased $(\mathrm{t}=1)+$ DaysStocked $(\mathrm{t}=0)$. In addition, DaysUsed $(\mathrm{t}=0)=$ DaysPurchased $(\mathrm{t}=0)$-DaysStocked $(\mathrm{t}=0)$.

Thus, DaysUsed $(\mathrm{t}=1)$-DaysUsed $(\mathrm{t}=0)=$ DaysPurchased $(\mathrm{t}=1)$-DaysPurchased $(\mathrm{t}=0)+2 \mathrm{~s}$. In other words, the difference in the DaysPurchased and DaysUsed coefficients is twice the day supply stocked.
} 


\section{Changes in out-of-pocket and total expenditures from increased use of generics}

Finally, equation 7 calculates the change in out-of-pocket or total expenditures from changes in generic (or low cost drug) use holding decisions about stocking $\left(s^{1}\right)$ and day supply $(Q)$ constant at the value observed in time period $t=1$. Negative numbers indicate greater savings.

$$
\begin{aligned}
\Delta E^{g}= & \left(E^{1} \mid g=g^{1}\right)-\left(E^{1} \mid g=g^{0}\right) \\
& =\Delta g\left[\left(1-s^{1}\right) P_{g}^{1} Q^{1}+s^{1} P_{g}^{0} Q^{1}-\left(1-s^{1}\right) P_{b}^{1} Q^{1}-s^{1} P_{b}^{0} Q^{1}\right]
\end{aligned}
$$

Savings are related to positive changes in generic or low cost drug use and with higher prices for branded drugs relative to generic prices. Reductions are smaller with higher prices for generic drugs. In order to calculate equation (7), we obtain prices, the generic fraction, and days used per month using claims data for CDHP firm 1. The change in generic drug use is from the estimated regression coefficient from equation (1) when the outcome is generic or low cost drug use.

\section{Data}

\subsection{Data sources and sample}

The data for the study include 100 percent of pharmaceutical claims and insurance enrollment information from 2004-2006 for employees (and dependents) of two firms that shifted virtually all employees to a CDHP in 2005 and 19 other firms that did not offer CDHPs during the 2004-2006 health plan years. These firms were drawn from a 63-firm panel constructed for an earlier study. Of these 63 firms, 35 offered a CDHP between 2003 and 2007 and the remaining 28 were chosen from the Truven Health MarketScan Research Database to match the geographic location, firm size, and industry characteristics of a larger set of employers offering CDHPs or high deductible health plans between 2003 and 2007; this process is described in more detail in Buntin et al. (2011). We selected the two CDHP firms from the 35 
CDHP offering firms specifically because they shifted virtually all employees to a CDHP in 2004 (relative to other firms where CDHP enrollment was optional). We excluded 9 of the 28 matched control firms because they either offered a CDHP or high deductible plan during the sample period, or in one case because of missing pharmaceutical claims data.

Our base sample includes employees or dependents in the 21 firms that used a statin, antihypertensive, or diabetes drug in the first nine months of 2004 and were enrolled in health coverage through the same employer for 12 months in 2005 for the sample measuring one-year effects or in both 2005 and 2006 for the sample measuring two-year effects. (We use the first nine- months of 2004 to measure pre-CDHP use, because CDHP anticipation effects may occur in the quarter prior to CDHP adoption.) Because we focus on health plan enrollees already using chronic drugs in 2004, we do not look at initiation of drug therapies and any reduction in utilization can be interpreted as reduced adherence or discontinuation of therapy.

Table 2 displays changes in sample size for the base cohort and the sample size (and retention relative to the base cohort) as enrollment restrictions are imposed. Column 1 shows the base sample that counts the number of individuals with a drug claim in January through September 2004. Adding the restriction of 12 months of enrollment in 2005 (i.e., the first year sample), the retention rate relative to the base sample is 58 to 62 percent (across drug samples) in CDHP firm 1, 67 to 69 percent in CDHP firm 2, and 75 to 77 percent in the firms with traditional plans, implying higher turnover in CDHP firm 1. Once requiring 12 months of enrollment in 2005 and 2006 (the sample for the two-year effects), the retention rate falls to 46 to 50 percent for CDHP firm 1, 43 to 45 percent for CDHP firm 2, and 63 to 66 percent for firms with traditional plans. 
If the higher attrition in CDHP firms 1 and 2 is in response to the mandatory shifting to the CDHP (for example, employees shift to their spouses' employer plans), the remaining sample may differ and exhibit differential responses than those that left the sample. We explore the extent to which attrition may be in response to CDHP adoption in the results section. First, we test for differential characteristics between attritting enrollees and those continuously enrolled. Next, we examine attrition in CDHP firms 1 and 2 for other years to examine whether these firms exhibit higher turnover independently from CDHP adoption (for example, CDHP firm 1 is in the retail sector, and thus may exhibit higher turnover). Finally, we re-estimate the main analysis with a sample of enrollees using drugs later in 2004 and less likely to leave the sample in 2005 .

\subsection{Study measures}

The four main study measures are constructed at the enrollee by month level for each drug category: (1) days supply purchased, (2) total drug spending, (3) drug out-of-pocket spending, and (4) fraction of days supply purchased that are generic or low cost drugs. First, we examine changes in days supply, spending, and low cost percentage by month of purchase. As described above, CDHP enrollees may “stock” drugs, purchasing drugs during periods of low cost sharing but then actually using the drugs later when cost sharing is higher. Not accounting for the difference between the timing of purchase and use may lead to biased estimated effects of CDHPs. For example, if patients stock up on drugs the month before CDHP implementation and then do not purchase drugs the first months after CDHP implementation, it may inaccurately appear that adherence has fallen. Reflecting this, we construct adjusted versions of the study measures that are based on an approximated month of use rather than the month of purchase. To approximate a month of use, we perform the following procedure. 
For each enrollee and month, we construct a "stock" of days supply and a "flow" of new days supply (separately for each drug category), where the "stock" includes days supply for a particular drug category that carried over from the prior month and the "flow" are new drugs purchased. If the stock and flow of days supply surpass 30 when summed, we assume that an enrollee will first take the stock drugs before using the new flow drugs. Any amount of days supply surpassing 30 will carry over to the next month as stock. Associated with the stock is a total price, an out-of-pocket price, and a generic (or low cost) fraction that are weighted averages of prices and generic status of the remaining stock and flow from the prior month. For example, if an enrollee purchased a 40-day supply in month $t$ of a generic statin and a 20-day supply in month $t+1$ of a brand name statin, the adjusted days supply would be 30 -days for each month, and the generic fraction would be 100 percent in month $t$ and 33 percent in month $t+1$. An assumption implicit in this method is that enrollees will take all of the supply that they purchased, which likely overstates adherence.

An additional complicating factor is that individuals with type 2 diabetes often take more than one drug in the included classes. In order to distinguish between individuals prescribed two 30-day supplies within a drug category from stocking behavior or switching drugs, we identify individuals as requiring 60-days supply per month if we observe two unique drug products obtained within a month across two months in 2004 . Then, we use a similar rule to create adjusted measures of days supply used per month as above, except that we only consider stocking if an individual obtained more than 60-days supply in one month.

\subsection{Description of sample}

Table 3 describes the firms, health plan enrollees, and drug utilization in our sample. The first panel displays characteristics of the beneficiaries in our sample in 2004 (i.e. using the drugs 
in the three categories described above) by treatment category. Notable differences across firms include that CDHP firm 1 enrollees are more likely to be from zip codes with more black residents and CDHP firm 1 and CDHP firm 2 enrollees are more likely to be female than the control firms. In sensitivity analyses in the results section, we explore the influence of these differences on the results by re-estimating the main analysis with a reweighting of the control firms to resemble CDHP firms 1 and 2 (separately).

The second panel displays characteristics of monthly pharmaceutical utilization across firms in 2004. Average days supply is significantly below 30 for each drug category and firm category, implying that patients are non-adherent at baseline. Average monthly spending is similar across treatment and control firms, but the CDHP firms exhibit higher out-of-pocket spending in the pre-period, which is consistent with the CDHP firms setting higher copayment tiers than the control firms in Table 1.

\section{Results}

\subsection{Descriptive results}

Figure 1 plots actual out-of-pocket expenditures per day supply over the sample period for CDHP firms 1 (solid line) and 2 (dotted line) and the control firms (dashed line) for the sample of enrollees using drugs in January through September 2004 and enrolled in plans for 12 months in both 2005 and 2006, separately by drug category. Panel (a) plots out-of-pocket expenditures for statins and shows that trends and levels are roughly similar across the three treatment groups in the pre-period. Out-of-pocket expenditures per day supply spike for CDHP firm 1 with the CDHP implementation in January 2005 before gradually falling over the course of the year as enrollees reached the deductible and spike again at the beginning of the 2006 . 
Some of the out-of-pocket expenditures early in the year are likely paid by health reimbursement accounts. In contrast, out-of-pocket expenditures for CDHP firm 2 and the comparison firms with traditional health plans stay approximately constant over the entire sample period. Panels (b) and (c) show similar patterns for antihypertensive and diabetes drugs, although the spikes for CDHP firm 1 are less pronounced, reflecting the greater availability of generics for these classes during the sample period.

Figure 2 displays days supply purchased in each month over the sample period for each treatment group by drug category. The results are generally consistent across drug categories: the solid line, representing CDHP firm 1, implies a large increase in purchases in the months prior to CDHP adoption in January 2005 followed by a large reduction in purchases in the months following adoption in early 2005 , with a similar if somewhat attenuated pattern at the end of 2005 going into 2006. CDHP firm 2 exhibits the same pattern as CDHP firm 1 but with smaller magnitude at the end and beginning of each year. In contrast, days purchased are relatively smooth for the comparison firms. In addition, the overall level of purchases falls for CDHP firm 1 relative to CDHP firm 2 and the comparison firms. Comparing Figures 1 and 2 suggests that enrollees in CDHP firm 1 respond to cost sharing incentives by stocking up on drugs in the months prior to CDHP implementation and at the end of the plan year in 2005, and by reducing overall utilization. Notably, CDHP firm 1 enrollees reduce purchase of drugs early in 2005 when medical expenses could be defrayed by a full HRA (HRA balances per month shown in Appendix Figure A.1); this may suggest that enrollees consider HRA funds as income rather than health coverage. Appendix Figure A.2 shows an increase in days supply purchased in the month when CDHP firm 1 enrollees reach the deductible. 
Figure 3 plots estimated days used per month for CDHP firms 1 and 2 and firms with conventional plans and shows relative reductions in use for CDHP firm 1 even when smoothing stocking of drugs over the year for each drug category.

Figure 4 plots the percentage of days supply used each month that are a lower price drug (generic statins for statins in panel (a), ACE inhibitors for antihypertensives in panel (b), and sulfonylureas and metformin for diabetes in panel (c)). Panel (a) shows similar trends across treatment groups in use of lovastatin, the only generic statin, from 2004 to 2005; however, when generic simvastatin becomes available in mid-2006, CDHP firm 1 enrollees are quicker and more likely to adopt generic drugs relative to CDHP firm 2 enrollees or firms with conventional plans. In panel (b), CDHP firm 1 employees are more likely to continue to use of ACE inhibitors than comparison firms and in panel (c) the proportion of days used that is sulfonylureas and metformin-only therapies increases, while low price drug utilization remains relatively constant for CDHP firm 2 and the comparison firms.

The descriptive evidence suggests that enrollees in CDHP firm 1, where prescriptions were subject to the deductible, respond to incentives along all three margins: by switching to generics or low class drugs when they were available and effective, by shifting the timing of purchase to periods of lower cost sharing, and by reducing overall utilization. In contrast, CDHP firm 2 enrollees' behavior is closer to that of enrollees in traditional plans. Finally, the similarity of the trends across CDHP firms 1 and 2 in 2004 prior to the anticipation period supports the identification assumption, that the comparison firms display the utilization behavior that would have occurred in CDHP firms 1 and 2 without CDHP adoption. 


\subsection{Year 1 CDHP effects}

Next, we formally estimate the effects of CDHP adoption on enrollees' pharmaceutical utilization. Table 4 displays estimates of year 1 CDHP effects for CDHP firm 1: panel A shows estimates for statins, panel B for antihypertensive drugs, and panel C for diabetes drugs. Each cell displays the estimate of $\theta$ from equation (1), corresponding to the differential change in the outcome for CDHP firm 1 relative to the comparison firms. Under the estimate in parentheses is the ranking of the coefficient relative to the placebo estimates from the 19 comparison firms, where a ranking of "1" indicates that CDHP firm 1 is most extreme relative to the one-sided null hypothesis and thus statistically significant.

Panel A, column 1 shows that total spending (including plan payments and out of pocket spending) for statins fall by $\$ 12.33$ per month for CDHP firm 1 relative to the comparison firms, and this is the most negative estimate among those in the permutation tests. Column 2 shows estimates for adjusted spending, approximating the month of use rather than timing of purchase to allow for stocking behavior. In this case, the reduction in spending falls to $\$ 7.76$, but it is still statistically significant. Columns 3 and 4 show changes in days supply based on month of purchase and approximate month of use. CDHP firm 1 enrollees purchase over three days less supply of statins per month in 2005 relative to traditional plan enrollees and this is statistically significant. Examining approximate days supply used in column 4, enrollees use 1.85 fewer days of statins per month and this estimate is also statistically significant. The difference in the CDHP effect on days supply purchased versus approximated month of use implies that enrollees stocked drugs from the pre-CDHP period when cost sharing was lower. Columns 5 and 6 display changes in use of generic statins, based on month of purchase and approximate month of use, and show no differential change in generic use relative to the comparison firms. 
Table 4, panel B displays year 1 effects for antihypertensive drugs and CDHP firm 1. Columns 1 and 2 show smaller reductions in antihypertensive payments, but columns 3 and 4 show similar reductions in days supply relative to statins. In contrast to statins, CDHP firm 1 enrollees increase their purchase and use of low-price drugs (defined as ACE inhibitors versus ARBs) by one percentage point relative to traditional plan enrollees, but only the use coefficient is statistically significant. In Table 4 panel C, CDHP firm 1 enrollees reduce payments and days supply (based on month of purchase and month of use) for diabetes drugs; again the differential suggests stocking behavior. Columns 5 and 6 show increased purchase and use of the low-price class (metformin and sulfonylureas, relative to glitazones with or without metformin and sulfonylureas) of five and three percentage points respectively. In each case, the estimates are statistically significant.

In summary, Table 4 suggests for statins, where the low cost alternative (lovastatin) was inferior in efficacy to branded drugs like Lipitor, enrollees respond to higher cost sharing by shifting the timing of purchase and reducing total utilization, but not by shifting to lower cost drugs. Year 1 CDHP effects on antihypertensive and diabetes drug utilization for CDHP firm 1 are similar to statins in terms of stocking and reductions in utilization. In contrast to statins, we find increased use of the low price classes for CDHP firm 1 for both antihypertensive and diabetes drugs. This finding may reflect that the low cost classes for antihypertensive and diabetes drugs are equally or more effective than the higher cost drugs.

Table 5 displays estimated year 1 effects for CDHP firm 2, where prescriptions were exempt from the deductible. Across drug categories, CDHP firm 2 exhibits reductions in total spending, based on month of purchase or approximate month of use. However, the reductions are smaller in magnitude than CDHP firm 1 and usually in the middle of the distribution of 
comparison firms and thus not statistically significant. In columns 3 and 4, CDHP firm 2 exhibits reductions in day supply, based on month of purchase or approximate month of use, that are more extreme than the comparison firms for antihypertensive and diabetes drugs, though also smaller in magnitude than CDHP firm 1 (results are statistically significant for 3 of 4 estimates and marginally significant for the fourth). CDHP firm 2 does not increase use of low cost drugs for any of the drug classes. The reductions in days supply in year 1, without a commensurate change in generic use, may imply a "gatekeeper" effect from higher cost sharing for physician visits rather than a misunderstanding of plan design, as there is no change in copayment tiers or cost sharing for generic or branded drugs after CDHP adoption for CDHP firm 2 (as shown in Table 1).

\subsection{Year 2 CDHP effects}

Table 6 displays estimated CDHP effects in years 1 and 2 for CDHP firm 1, with a sample restricted to employees who used the included drug categories in 2004 and were continuously enrolled in both 2005 and 2006. Here we only examine utilization based on approximated timing of use rather than month of purchase. Panel A displays results for statins. Column 1 shows that the point estimate for days used in 2005 is negative and similar in magnitude to the one-year sample. By 2006 the effect is smaller, but still the second largest among firms in the sample (and thus marginally significant). In column 2, use of low cost drugs (in this case, generic statins) does not change for CDHP firm 1 in 2005 relative to the comparison firms, but increases by three percentage points relative to the comparison firms in 2006, but neither point estimate is statistically significant. This estimated increase reflects the availability of generic simvastatin in mid-2006; however, the increase for CDHP firm 1 is only the fifth largest relative to the comparison firms. Columns 3 and 4 show persistent and 
statistically significant or borderline significant reductions in days supply used for antihypertensive drugs and increased use of lower cost ACE inhibitors relative to ARBs. Column 5 shows a smaller reduction in days used for diabetes in 2006 that is only marginally statistically significant. Column 6 shows that the increased percentage of days supply of diabetes drugs that was lower cost remained statistically significant in 2006 .

Table 7 displays results for CDHP firm 2. For each class, first year point estimates for the two-year sample are attenuated relative to CDHP firm 1 and statistically insignificant (with the exception of days used for the diabetes sample). In contrast, the second year point estimates imply statistically significant reductions in days used that are larger in magnitude for statins and diabetes drugs than those for CDHP firm 1. The change in proportion of days used that is generic relative to the comparison firms is statistically insignificant. These results could reflect either misunderstanding of benefit design (i.e., drugs are not subject to the deductible) or a reduction in access to drugs due to higher cost sharing for physician visits. The results in Table 7 may suggest the reduced access mechanism rather than misunderstanding benefit design for two reasons. First, if the reduction is due to misunderstanding benefit design, it may be less likely to persist into the second year of the plan. Second, we find no change in the proportion of days used that are low cost (as mentioned above). The lack of a change in low cost drugs is consistent with beneficiaries understanding that cost sharing did not change for these drugs.

\subsection{Year 1 event study}

Next, we investigate in more detail the dynamics of drug purchase and use in the first year of the CDHP in CDHP firm 1. Table 8 displays estimates similar to equation (1) for days supply purchased and used, except instead of including a single "POST $2005 \times$ CDHP" 
interaction term, we include separate bimonthly interaction terms from the two months prior to CDHP implementation through the end of the first year.

In column 1, there is spike in days supply purchased of 4.24 days per month for statins in the two months prior to CDHP implementation and a subsequent dip in purchases of 4.23 days per month (both of which are statistically significant). Days purchased in CDHP firm 1 then converge with the comparison firms by months $9-10$ of 2005 , presumably as enrollees reach the deductible and out-of-pocket spending falls. Column 2 shows a smaller spike in days used in the two months prior to CDHP implementation relative to the comparison firms (2.03 days used versus 4.24 days supply purchased and statistically significant) and a smaller reduction in days supply used compared to days supply purchased in the first two months of 2005 (-1.10 versus 4.23 and marginally significant) which again continues until months 9-10 of 2005. Columns 3-6 show similar patterns for antihypertensive and diabetes drugs. The difference in coefficient estimates between models using month of purchase versus month of use, contrasted with cost sharing over the sample period, implies that enrollees purchased drugs in periods of high cost sharing for use during periods of low cost sharing. In contrast, Table A.2 displays estimates for CDHP firm 2 and shows little evidence of differences in timing of purchases.

\subsection{Decomposition of effects}

In Table 9, we contrast the size of effects in CDHP firm 1 along the timing, overall utilization, and low cost drug margins for each drug category using a post-estimation decomposition exercise described in section 3.3, separately for out-of-pocket and total spending. Specifically, we compare spending from 2005 utilization behavior with 2005 levels of cost sharing relative to 2004 utilization behavior with 2005 levels of cost sharing. These estimates 
combine observed utilization and prices in 2004 and 2005 in CDHP firm 1 with behavior changes from estimating equation 1 for each outcome.

The top panel displays decomposition results for out-of-pocket spending. The first row shows out-of-pocket savings per month stemming from changes in the timing of purchase of drugs. For statins, changing the timing of purchases represented 10 percent of total savings across the three response margins. The timing percentages for antihypertensive and diabetes drugs were $>1$ percent and 10 percent, respectively. The timing effects are small in part because they are averaged across 2005 while the savings only accrue in the early part of the year, effectively diluting the effect.

The majority of out-of-pocket savings for each drug class originates from reductions in overall utilization, representing 90 percent and 93 percent of total savings for statins and antihypertensive drugs respectively, and 58 percent of total savings for diabetes drugs. Low cost drug use results in no out-of-pocket savings for statins, as we found no change in generic statin use. For antihypertensive drugs, we find that 7 percent of total savings came from increased use of ACE inhibitors (driven by the modest increase in ACE inhibitor use). For diabetes drugs, we estimate a more substantial increase in use of low cost drugs (sulfonylureas and metformin) compared to the comparison firms, comprising 33 percent of total savings from across the three response margins. Total monthly out-of-pocket savings across the three margins are the largest for statins (\$4.31), followed by diabetes (\$2.04) and antihypertensive drugs (\$1.61), representing 10 to 20 percent of monthly out-of-pocket spending on the drug class in 2004, implying that utilization responses do lead to substantial savings for employees in CDHP firm 1.

The second panel displays decomposition results for total spending. Because the switch to CDHP did not have a direct effect on the total price of the drug, the timing margin results in 
no total savings, and in fact led to increased total expenditures, as total prices were lower for these drug classes in 2005 (which could occur because of competition from generics or larger discounts for CDHP firm 1). Thus, stocking actually increased total expenditures. Reduction in utilization was again responsible for the majority of total spending for each class (ranging from 66 percent for diabetes drugs to 101 percent for statins), with low cost drug use leading to no savings for statins, but 7 and 37 percent of reductions in total monthly expenditures for antihypertensive and diabetes drugs.

\subsection{Sensitivity analyses}

We identified two empirical patterns in our analysis that could threaten the validity of our results. First, we find higher attrition in the year of CDHP adoption for CDHP firm 1, and to a lesser extent CDHP firm 2, than the control firms with traditional plans. Second, we find differences in the characteristics of enrollees in CDHP firms 1 and 2 relative to the firms with traditional plans. In this section, we explore these issues.

\section{Differential attrition}

As shown in Table 2, the percentage of plan enrollees using the included drug categories in January through September 2004 that are enrolled in a plan offered by the firm for 12 months in 2005 (and 12 months in both 2005 and 2006) is lower for CDHP firm 1 than CDHP firm 2, and retention rates for CDHP firm 1 and 2 are both lower than the control firms. If enrollees selectively drop employer-provided coverage from CDHP firms 1 and 2 because of the switch to a CDHP (for example, to take-up a spouse's coverage), then our estimates may reflect the behavior just of enrollees choosing to stay, who may differ systematically than those dropping coverage. 
In Appendix Table A.2, we examine the characteristics of enrollees using the included drug categories in January through September 2004, but without 12 months of enrollment in 2005 and 2006 versus enrollees using the included drug categories in January through September 2004 with 12 months of enrollment in both 2005 and 2006. Gender and age are sometimes misassigned within family for individuals enrolled in CDHP firms 1 and 2 just during 2004, so we focus on zip code level characteristics and the number of major diagnostic categories (25 mutually exclusive categories that are identified based on ICD-9 codes on outpatient and inpatient visit claims and pertain to a single organ system). Enrollees in CDHP firm 1 present in just 2004 had fewer MDCs (3.7) than those enrolled continuously through 2006 (4.4). We find a similar pattern of results in CDHP firm 2 and control firms, with enrollees present in just 2004 exhibiting fewer MDCs than those present continuously through 2006. For CDHP firms 1 and 2, enrollees dropping coverage after 2004 exhibit similar zip-code level demographic characteristics as those continuously enrolled (with the exceptions of the percentage graduating from high school for CDHP firm 1 and the percentage white for CDHP firm 2). Differences in characteristics by continuous enrollment are more often statistically significant for control firms, but this are largely due to higher sample sizes; the average characteristics are similar. In summary, this evidence implies that enrollees dropping coverage in CDHP firms 1 and 2 are similar on many characteristics to enrollees continuously enrolled, and the levels and patterns by sample tenure for health status are similar across all firms.

Next, we examine whether retention rates for CDHP firm 1 and 2 were consistently lower than the control firms, or if the lower retention rates only occurred with the introduction of the CDHP in 2005. Table A.3 displays the retention rate for each drug category, treatment group, and year. The retention rate for each year is defined as the percentage of individuals with a drug 
claim between January and September of a year that are continuously enrolled in the firm's health coverage in the following year (i.e., consistent with our inclusion criteria). Column (1) for 2004 displays the same retention estimates from column (2) in Table 2. Columns (2) and (3) show that retention rates for CDHP firm 1 were slightly higher in 2005 relative to 2004 and lower in 2006 relative to 2004. Retention rates for CDHP firm 2 were lower in 2005 relative to 2004 and slightly higher in 2006 relative to 2004. Retention rates were similar across all years for the control firms. The results in Table A.3 suggest that CDHP firms 1 and 2 consistently exhibit lower retention, and thus the higher turnover rates from 2004 to 2005 may not have been in response to the introduction of the CDHP. As described above, CDHP firm 1 is in the retail sector and this may contribute to higher turnover.

Finally, we focus on enrollees in CDHP firm 1 and the control firms that used a drug in July through September 2004 rather than January through September 2004. Table A.4 shows that this restriction reduces the sample size, but increases the retention rate by five to eight percentage points across drug categories in CDHP firm 1 and by four percentage points in the control firms. In Table A.5, we re-estimate the main regressions to examine whether the lessselected sample exhibits different responses, and find very similar estimates across each response margin to Table 4 .

\section{Differences in firm composition}

As shown in the summary statistics in Table 3, the zip code level demographic characteristics of CDHP firms 1 and 2, in particular, differ from the control firms. We examine the sensitivity of the results to these differences by reweighting the control firms to better resemble CDHP firms 1 and 2 using an inverse propensity score weighting approach. As our analysis is estimated at the firm level, we individually match each control firm separately to 
CDHP firms 1 and 2. We estimate logit regressions that include zip code level median household income, unemployment rate, percentage high school graduate, percentage college graduate, percentage black, percentage Hispanic, and percentage white. For each individual in the control firm sample, we assign a predicted odds-ratio of being in CDHP firm 1 or 2 . This "weighting by the odds" approach leads to an estimate of the average treatment effect on the treated (Harder, Stuart, and Anthony 2010; Hirano, Imbens, and Ridder 2003). We then recalculate firm-level monthly averages using the predicted odds-ratio as a sample weight and re-run the one-year analyses.

Table A.6 displays the results of the matching exercise for CDHP firm 1 for each drug category sample. The first column displays average characteristics for CDHP firm 1, the second and third columns display the average of unweighted firm-level means across the 19 control firms and the number of firms with a standardized difference under 0.25 for the characteristic of interest relative to CDHP firm 1, and the fourth and fifth columns show the average of weighted firm-level means across the 19 control firms and the number of firms with a standardized difference less than 0.25 using the weighted means relative to CDHP firm 1 (where the 0.25 is a commonly used benchmark for the maximum allowable standardized difference (Harder et al. 2010)). The weighting procedure substantially improves the balance of CDHP firm 1 relative to the control firms, with 16 to 19 of control firms exhibiting standardized differences less than 0.25 across characteristics for the statins sample, 16 to 18 for antihypertensive drugs, and 14 to 17 for diabetes. Table A.7 displays the year 1 effects for CDHP firm 1 with the reweighted control firms. The estimates are very similar to Table 4, with the notable exception that the use of low cost drugs becomes statistically insignificant for the antihypertensive and diabetes drug samples. Table A.8 displays the results of the matching procedure for CDHP firm 2 and shows 
similar improvements in balance. Table A.9 displays year 1 effects for CDHP firm 2 with reweighted control firms and shows similar results to Table 5, except that the days supply effects for diabetes drugs become insignificant or marginally significant.

\section{Conclusion}

We investigate the effects of CDHPs on use of pharmaceuticals that treat and prevent chronic diseases including high cholesterol, hypertension, and type 2 diabetes. We compare changes in utilization among employees in two firms that shift all of their employees to CDHPs relative to employees in firms that offered no CDHP; in one firm (CDHP firm 1) pharmaceuticals are subject to the deductible and in the other pharmaceuticals are exempt from the deductible (CDHP firm 2). We find that enrollees in CDHP firm 1 change utilization of pharmaceuticals along each hypothesized margin: enrollees shift the timing of purchase to periods with lower cost sharing, increase the use of lower cost drugs (but only when such drugs were equally or more effective), and reduce overall pharmaceutical utilization. The majority of the response, however, is focused on the reduction in overall utilization. In addition, most of these effects persist into the second year of the CDHP. In CDHP firm 2, we observe insignificant changes in utilization for statins, but statically significant or marginally significant reductions in utilization of antihypertensive drugs and diabetes drugs. We observe no effect, however, on the percentage of days supply purchased or used that were low cost. The utilization effects for CDHP firm 2 are larger and statistically significant for all drug categories in the second year of the CDHP. We interpret the persistence of these effects, combined with the absence of a change in use of low cost drugs, as suggestive evidence of a "gatekeeper" effect, where higher cost sharing for physician visits result in reductions in pharmaceutical use. Moreover, some of the 
reduction in utilization in CDHP firm 1 could also be driven by a reduction in access to physician visits, a phenomenon observed in the RAND Health Insurance Experiment (Leibowitz, Manning, and Newhouse 1985).

The shifts in timing and increased use of lower cost drugs in CDHP firm 1 are both forward-looking and strategic responses to the incentives in CDHPs, implying both awareness of benefit design and effective lobbying of physicians to shift to lower cost alternatives. In addition, the timing margin implies that enrollees consider medium-term rather than static prices in making utilization decisions, consistent with Aron-Dine et al. (2012). In contrast, given the costeffectiveness of the drugs in the sample and the consequences for poor adherence, the reduction in overall utilization implies either a high discount rate or an incomplete understanding of the consequences of poor drug adherence. For example, Chandra et al. (2010) find that reductions in drug adherence after an increase in cost sharing in a supplemental retiree health plan led to increased hospital costs. This response may imply the need for additional deductible exemptions for drugs treating chronic disease, such as in "Value Based Insurance Design" (Fendrick and Chernew 2006). Finally, while the timing response implies sophisticated understanding of benefit design on the part of enrollees, it is also not the intent of CDHP adoption and highlights the perverse incentives created by nonlinear insurance contracts. 
Aron-Dine, A., L. Einav, A. Finkelstein, and M. Cullen. 2012. "Moral hazard in health insurance: how important is forward looking behavior? ." NBER Working Paper 17802.

Bolen, S., L. Feldman, J. Vassy, and et al. 2007. "Systematic Review: Comparative Effectiveness and Safety of Oral Medications for Type 2 Diabetes Mellitus." Annals of Internal Medicine 147: 386-99.

Buchmueller, T. C., J. DiNardo, and R. G. Valleta. 2011. "The Effect of an Employer Health Insurance Mandate on Health Insurance Coverage and the Demand for Labor: Evidence from Hawaii." American Economic Journal- Economic Policy 3: 25-51.

Bundorf, M. K. 2012. “Consumer-directed health plans: Do they deliver?” Research Synthesis Report. The Synthesis Project. Princeton, N.J.: Robert Wood Johnson Foundation.

Buntin, M. B., A. Haviland, R. McDevitt, and N. Sood. 2011. "Health care spending and preventive care in high-deductible and consumer-directed health plans." American Journal of Managed Care 17(3): 222-30.

Chandra, A., J. Gruber, and R. McKnight. 2010. "Patient Cost-Sharing and Hospitalization Offsets in the Elderly." American Economic Review 100(1): 193-213.

Charlton, M. E., B. T. Levy, R. R. High, J. E. Schneider, and J. M. Brooks. 2011. "Effects of Health Savings Account Eligible Plans on Utilization and Expenditures." American Journal of Managed Care.

Chobanian, A. V., G. L. Bakris, H. R. Black, and et al. 2003. "The Seventh Report of the Joint National Committee on Prevention, Detection, Evaluation, and Treatment of High Blood Pressure." JAMA 289(19): 2560-72.

Clarke, P., A. Gray, A. Adler, R. Stevens, and et al. 2001. "Cost-effectiveness analysis of intensive blood-glucose control with metformin in overweight patients with Type II diabetes (UKPDS No. 51).” Diabtologia 44: 298-304.

Conley, T. G. and C. R. Taber. 2011. "Inference with "differences in differences" with a small number of policy changes." The Review of Economics and Statistics 93(1): 113-25.

Cutler, D. M. and N. R. Sahni. 2013. "If Slow Rate of Health Care Spending Growth Persists, Projects May Be Off By $\$ 770$ Billion.” Health Affairs 32(5): 841-50.

Delea, T. E., J. S. Edelsberg, M. Hagiwara, G. Oster, and L. S. Phillips. 2003. "Use of thiazolidinediones and risk of heart failure in people with type 2 diabetes: a retrospective cohort study." Diabetes Care 26(11): 2983-9.

Fendrick, A. M. and M. E. Chernew. 2006. "Value-based insurance design: a "clinically sensitive" approach to preserve quality of care and contain costs." American Journal of Managed Care 12(1): 18-20. 
Fronstin, P., M.-J. Sepulveda, and M. C. Robebuck. 2013. "Medical Utilization and Adherence in a Health Savings Account-Eligible Plan." American Journal of Managed Care 19(12): e400e07.

Harder, V. S., E. A. Stuart, and J. C. Anthony. 2010. "Propensity score techniques and assessment of measured covariate balance to test causal associations in psychological research." Psychol Methods 15(3): 234-39.

Haviland, A., M. S. Marquis, R. D. McDevitt, and N. Sood. 2012. "Growth of ConsumerDirected Health Plans to One-Half of All Employer-Sponsored Insurance Could Save \$57 Billion Annually." Health Affairs 31(5): 1009-15.

Hirano, K., G. W. Imbens, and G. Ridder. 2003. "Efficient estimation of average treatment effects using the estimated propensity score." Econmetrica 71(4): 1161-89.

Jones, P., S. Kafonek, I. Laurora, and D. Hunninghake. 1998. "Comparative Dose Efficacy Study of Atorvastatin Versus Simvastatin, Pravastatin, and Fluvastatin in Patients With Hypercholesterolemia (The Curves Study).” American Journal of Cardiology 81: 582-87.

KFF and HRET. 2013. "Employer Health Benefits: 2013 Summary of Findings.” The Kaiser Family Foundation and Health Research and Educational Trust.

Leibowitz, A., W. G. Manning, and J. P. Newhouse. 1985. "The demand for prescription drugs as a function of cost-sharing." Social Science and Medicine 21(10): 1063-69.

Lo Sasso, A., L. A. Helmchen, and R. Kaestner. 2010. "The Effects of Consumer-Directed Health Plans on Health Care Spending.” The Journal of Risk and Insurance 77(1): 85-103.

Matchar, D. B., D. C. McCrory, L. A. Orlando, M. R. Patel, U. D. Patel, M. B. Patwardhan, B. Powers, G. P. Samsa, and R. N. Gray. 2008. "Systematic Review: Comparative Effectiveness of Angiotensin Converting Enzyme Inhibitors and Angiotensin II Receptor Blockers for Treating Essential Hypertension." Annals of Internal Medicine 148: 16-29.

Nissen, S. E. and K. Wolski. 2007. "Effect of rosiglitazone on the risk of myocardial infarction and death from cardiovascular causes." The New England Journal of Medicine 356(24): 2457-71.

Parente, S. T., R. Feldman, and S. Chen. 2008. "Effects of a consumer driven health plan on pharmaceutical spending and utilization." Health Services Research 43(5 Pt 1): 1542-56.

Ward, S., M. L. Jones, A. Pandor, M. Holmes, R. Ara, A. Ryan, W. Yeo, and N. Payne. 2007. "A systematic review and economic evaluation of statins for the prevention of coronary events." Health Technology Assessment 11(14).

Wharam, J. F., A. A. Galbraith, K. P. Kleinman, S. B. Soumerai, D. Ross-Degnan, and B. E. Landon. 2008. "Cancer screening before and after switching to a high-deductible health plan." Annals of Internal Medicine 148(9): 647-55. 
Figure 1: Out-of-pocket expenditures per day supply

(a) Statins

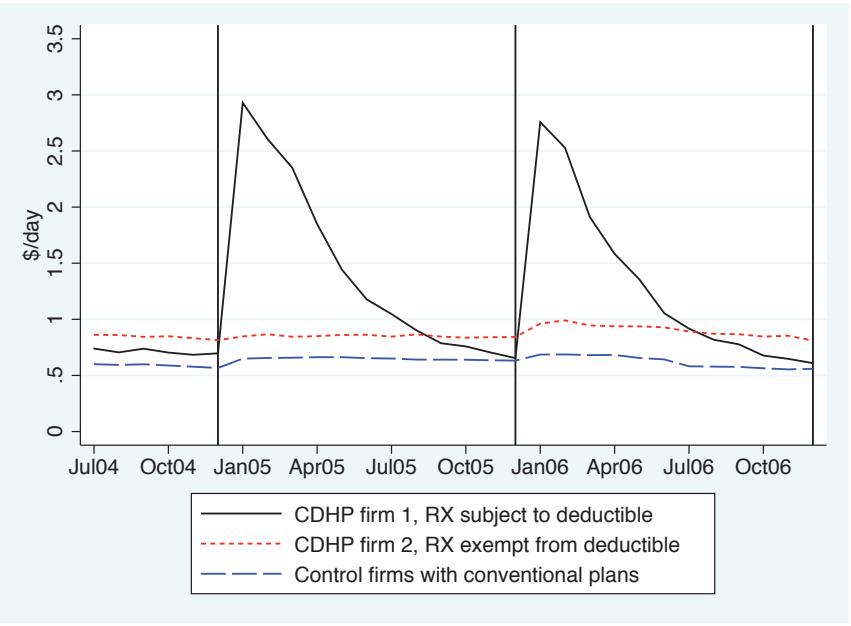

(c) Diabetes drugs

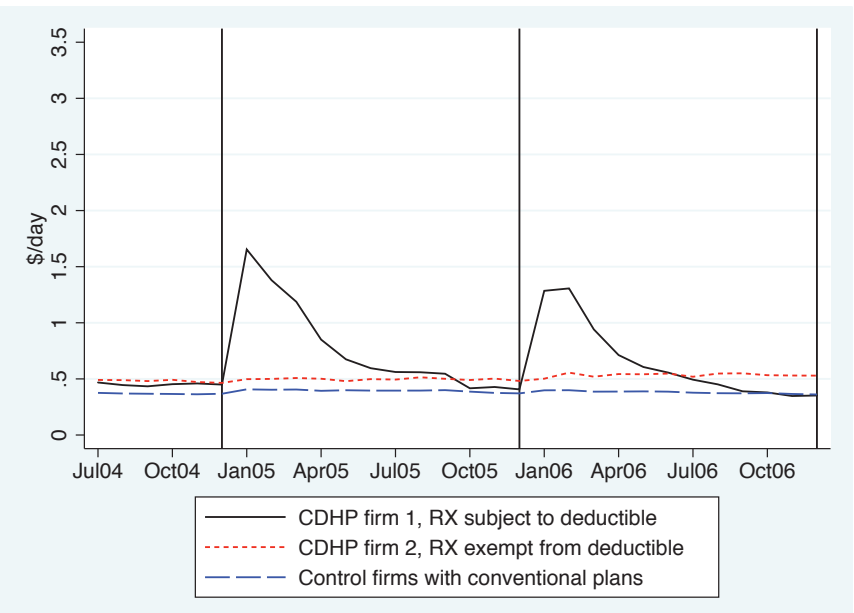

(b) Antihypertensives

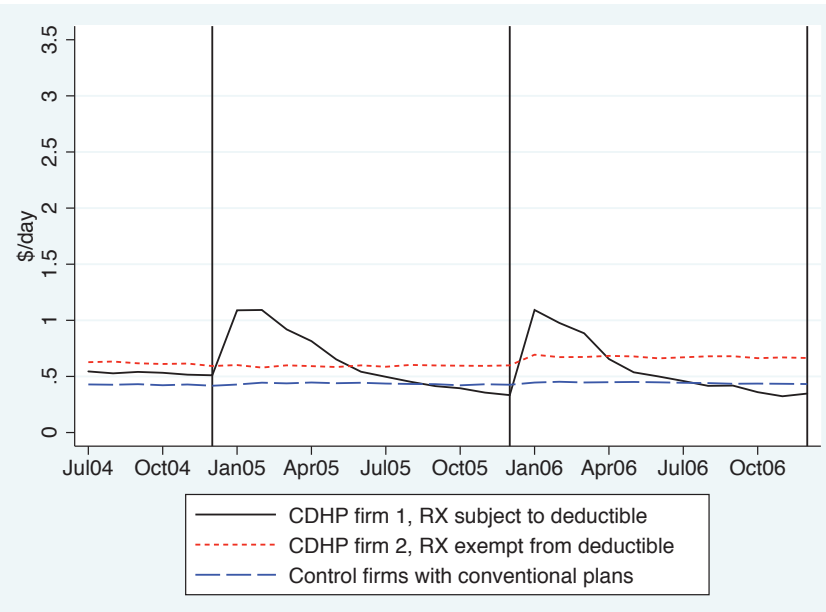

Note: Figures display average out-of-pocket expenditures per day supply purchased by CDHP-status. 
Figure 2: Days supply purchased

(a) Statins



(c) Diabetes drugs



(b) Antihypertensives

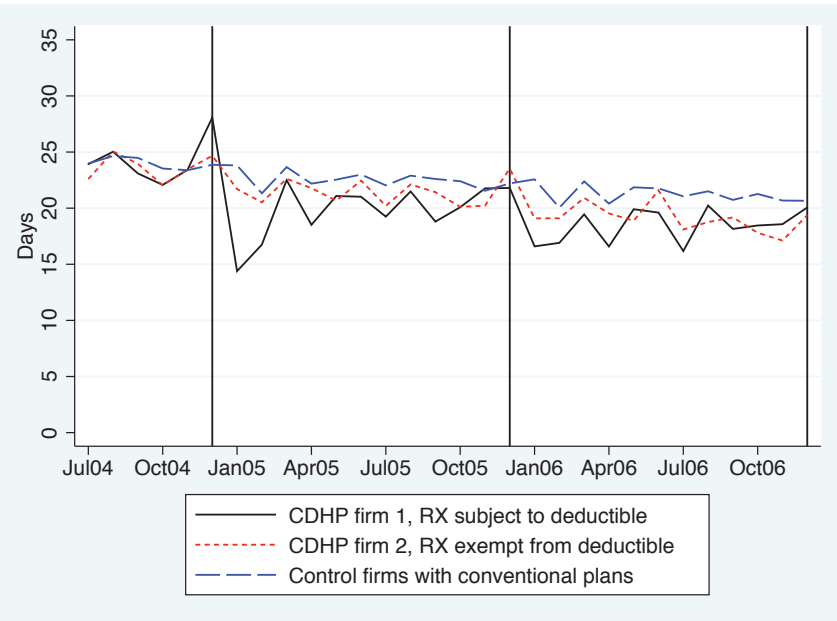

Note: Figures display average days supply purchased by CDHP-status. 
Figure 3: Days used per month

(a) Statins



(c) Diabetes drugs

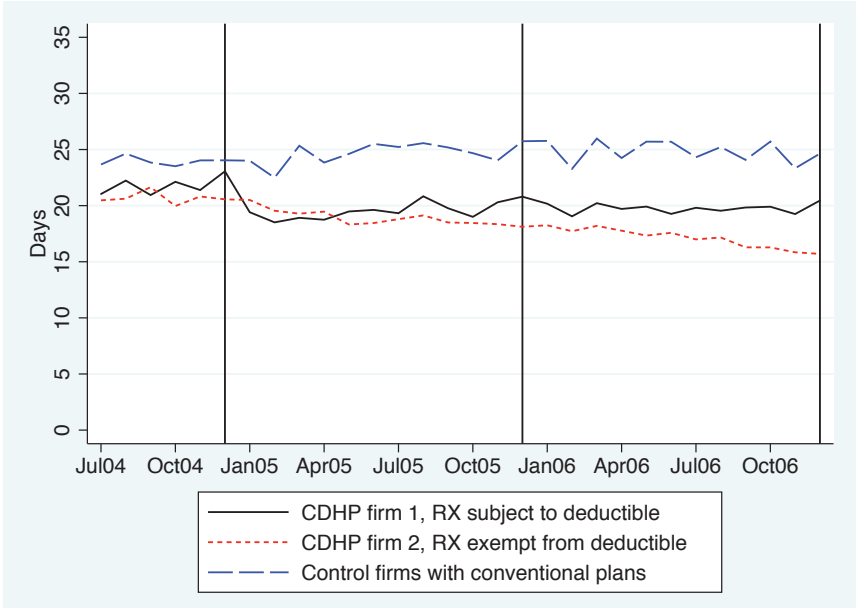

(b) Antihypertensives

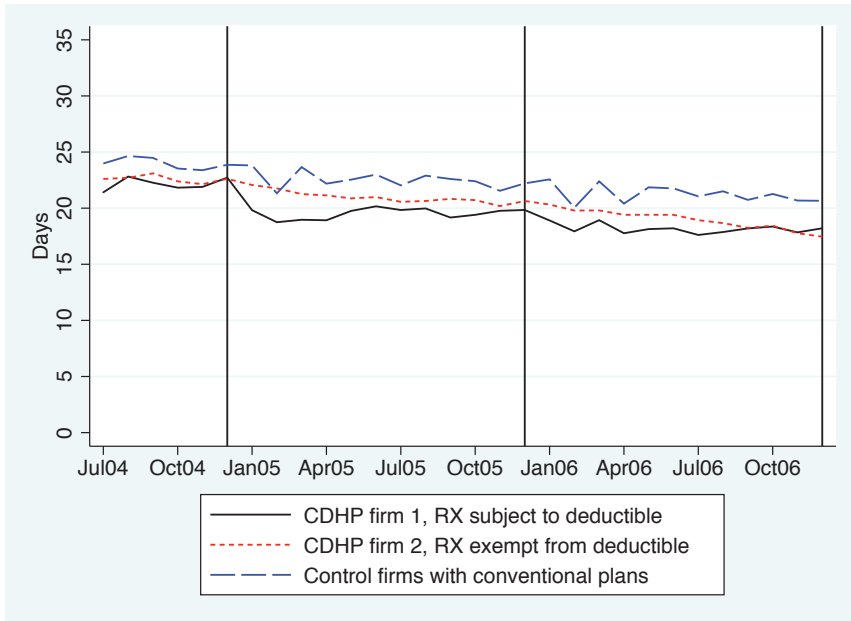

Note: Figures display average estimated days used per month by CDHP-status. 
Figure 4: Lower price drugs used

(a) Statins

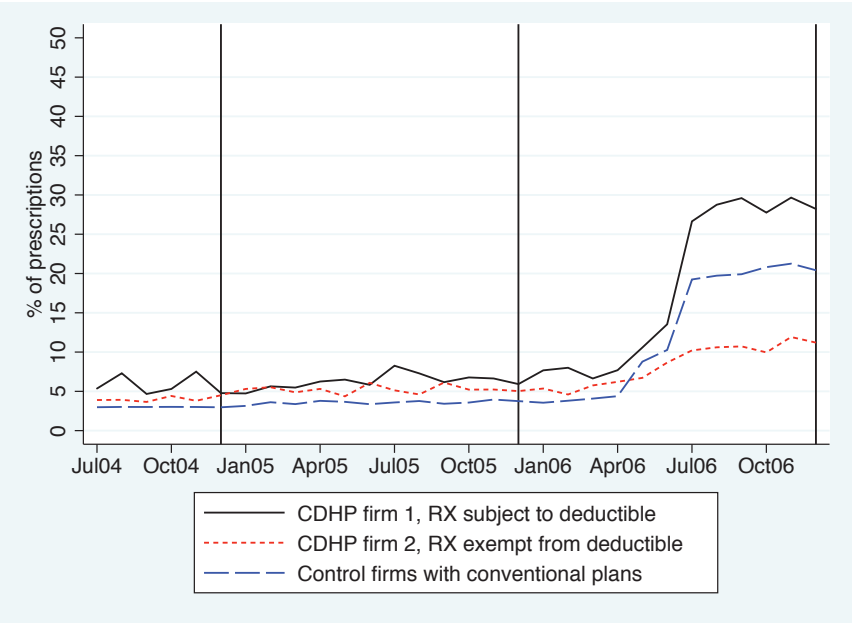

(c) Diabetes drugs

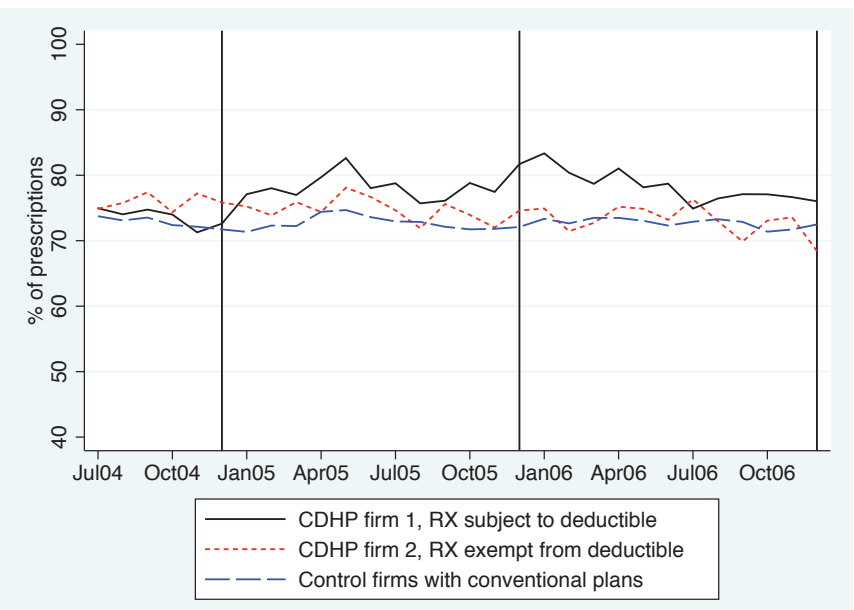

(b) Antihypertensives

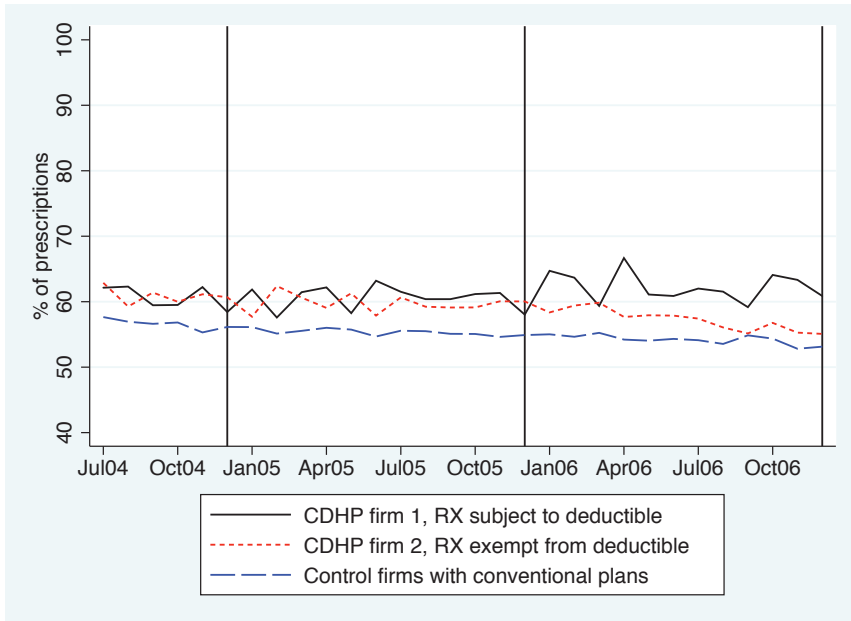

Note: Figures display percentage of days used that are low-cost by CDHP-status. 
Table 1: Health plan characteristics over the sample period

\begin{tabular}{|c|c|c|c|}
\hline & $\begin{array}{l}(1) \\
\text { Calendar year } \\
2004\end{array}$ & $\begin{array}{l}(2) \\
\text { Calendar year } \\
2005\end{array}$ & $\begin{array}{l}(3) \\
\text { Calendar year } \\
2006\end{array}$ \\
\hline \multicolumn{4}{|l|}{ CDHP firm 1: RX subject to deductible } \\
\hline $\begin{array}{r}\text { RX cost sharing }{ }^{1} \\
\text { Generic } \\
\text { Brand (formulary) } \\
\text { Brand (non-formulary) }\end{array}$ & $\begin{array}{l}\$ 10 \\
\$ 20 \\
\$ 35\end{array}$ & $\begin{array}{l}100 \% / 20 \% \\
100 \% / 20 \% \\
100 \% / 20 \%\end{array}$ & $\begin{array}{l}100 \% / 20 \% \\
100 \% / 20 \% \\
100 \% / 20 \%\end{array}$ \\
\hline $\begin{array}{r}\text { Average family deductible } \\
\text { High deductible percentage } \\
\text { Health care account } \\
\text { Employer account contribution (single/family) }\end{array}$ & $\begin{array}{l}\$ 54 \\
2 \% \\
0 \% \\
\$ 0\end{array}$ & $\begin{array}{c}\$ 1,998 \\
99.9 \% \\
99.9 \% \text { HRA } \\
\$ 500 / \$ 1000\end{array}$ & $\begin{array}{c}\$ 1,906 \\
73 \% \\
100 \% \text { HRA } \\
\$ 500 / \$ 1000\end{array}$ \\
\hline \multicolumn{4}{|l|}{ CDHP firm 2: RX exempt from deductible } \\
\hline $\begin{array}{r}\text { RX cost sharing } \\
\text { Generic } \\
\text { Brand formulary } \\
\text { Brand non-formulary }\end{array}$ & $\begin{array}{l}\$ 10 \\
\$ 25 \\
\$ 45\end{array}$ & $\begin{array}{l}\$ 10 \\
\$ 25 \\
\$ 45\end{array}$ & $\begin{array}{l}\$ 10 \\
\$ 27 \\
\$ 50\end{array}$ \\
\hline $\begin{array}{r}\text { Average family deductible } \\
\text { High deductible percentage } \\
\text { Health care account } \\
\text { Employer account contribution (single/family) }\end{array}$ & $\begin{array}{c}\$ 138 \\
3 \% \\
3 \% \text { HRA } \\
\$ 400 / \$ 1200\end{array}$ & $\begin{array}{c}\$ 2,176 \\
99.6 \% \\
92 \% \text { HRA }, 5 \% \text { HSA } \\
\$ 400 / \$ 1200\end{array}$ & $\begin{array}{c}\$ 3,167 \\
100 \% \\
91 \% \text { HRA, } 4 \% \text { HSA } \\
\$ 400 / \$ 1200\end{array}$ \\
\hline \multicolumn{4}{|c|}{ Control firms with conventional plans never offering CDHP } \\
\hline $\begin{array}{r}\text { RX cost sharing } \\
\text { Median generic copay } \\
\text { Median brand (formulary) copay } \\
\text { Median brand (non-formulary) copay }\end{array}$ & $\begin{array}{l}\$ 5 \\
\$ 16 \\
\$ 35\end{array}$ & $\begin{array}{l}\$ 5 \\
\$ 16 \\
\$ 30\end{array}$ & $\begin{array}{l}\$ 5 \\
\$ 16 \\
\$ 32\end{array}$ \\
\hline $\begin{array}{r}\text { Average family deduct } \\
\text { High deductible percentage } \\
\text { Health care account }\end{array}$ & $\begin{array}{l}\$ 113 \\
0 \% \\
0 \%\end{array}$ & $\begin{array}{l}\$ 143 \\
0 \% \\
0 \%\end{array}$ & $\begin{array}{c}\$ 202 \\
0 \% \\
<1 \% \text { HSA }\end{array}$ \\
\hline
\end{tabular}

${ }^{1}$ For CDHP firm 1, RX cost sharing is $100 \%$ prior to the deductible and $20 \%$ after the deductible. 
Table 2: Number of unique individuals using therapeutic classes and retention rates

\begin{tabular}{|c|c|c|c|}
\hline & $\begin{array}{c}(1) \\
\text { Used class in Jan-Sept } 2004\end{array}$ & $\begin{array}{c}(2) \\
\text { Used class in Jan-Sept 2004, } \\
\text { continuous enroll } 2005\end{array}$ & $\begin{array}{l}\text { (3) } \\
\text { Used class in Jan-Sept 2004, } \\
\text { continuous enroll 2005-2006 }\end{array}$ \\
\hline \multicolumn{4}{|c|}{ CDHP firm 1: RX subject to deductible } \\
\hline Statins & 1,118 & $\begin{array}{c}694 \\
(62 \%)\end{array}$ & $\begin{array}{c}560 \\
(50 \%)\end{array}$ \\
\hline Antihypertensives & 1,195 & $\begin{array}{c}727 \\
(61 \%)\end{array}$ & $\begin{array}{c}580 \\
(49 \%)\end{array}$ \\
\hline Diabetes drugs & 685 & $\begin{array}{c}399 \\
(58 \%)\end{array}$ & $\begin{array}{c}318 \\
(46 \%)\end{array}$ \\
\hline \multicolumn{4}{|c|}{ CDHP firm 2: RX exempt from deductible } \\
\hline Statins & 3,143 & $\begin{array}{l}2,159 \\
(69 \%)\end{array}$ & $\begin{array}{l}1,425 \\
(45 \%)\end{array}$ \\
\hline Antihypertensives & 3,353 & $\begin{array}{l}2,267 \\
(68 \%)\end{array}$ & $\begin{array}{l}1,469 \\
(44 \%)\end{array}$ \\
\hline Diabetes drugs & 1,404 & $\begin{array}{c}937 \\
(67 \%)\end{array}$ & $\begin{array}{c}602 \\
(43 \%)\end{array}$ \\
\hline \multicolumn{4}{|c|}{ Control firms with conventional plans never offering CDHP } \\
\hline Statins & 177,695 & $\begin{array}{c}136,481 \\
(77 \%)\end{array}$ & $\begin{array}{c}116,612 \\
(66 \%)\end{array}$ \\
\hline Antihypertensives & 163,444 & $\begin{array}{c}124,597 \\
(76 \%)\end{array}$ & $\begin{array}{c}106,205 \\
(65 \%)\end{array}$ \\
\hline Diabetes drugs & 62,344 & $\begin{array}{l}46,562 \\
(75 \%)\end{array}$ & $\begin{array}{c}39,034 \\
(63 \%)\end{array}$ \\
\hline
\end{tabular}

Note: Table displays number of enrollees and retention rate relative to number of enrollees using class in January through September 2004. 
Table 3: Summary statistics

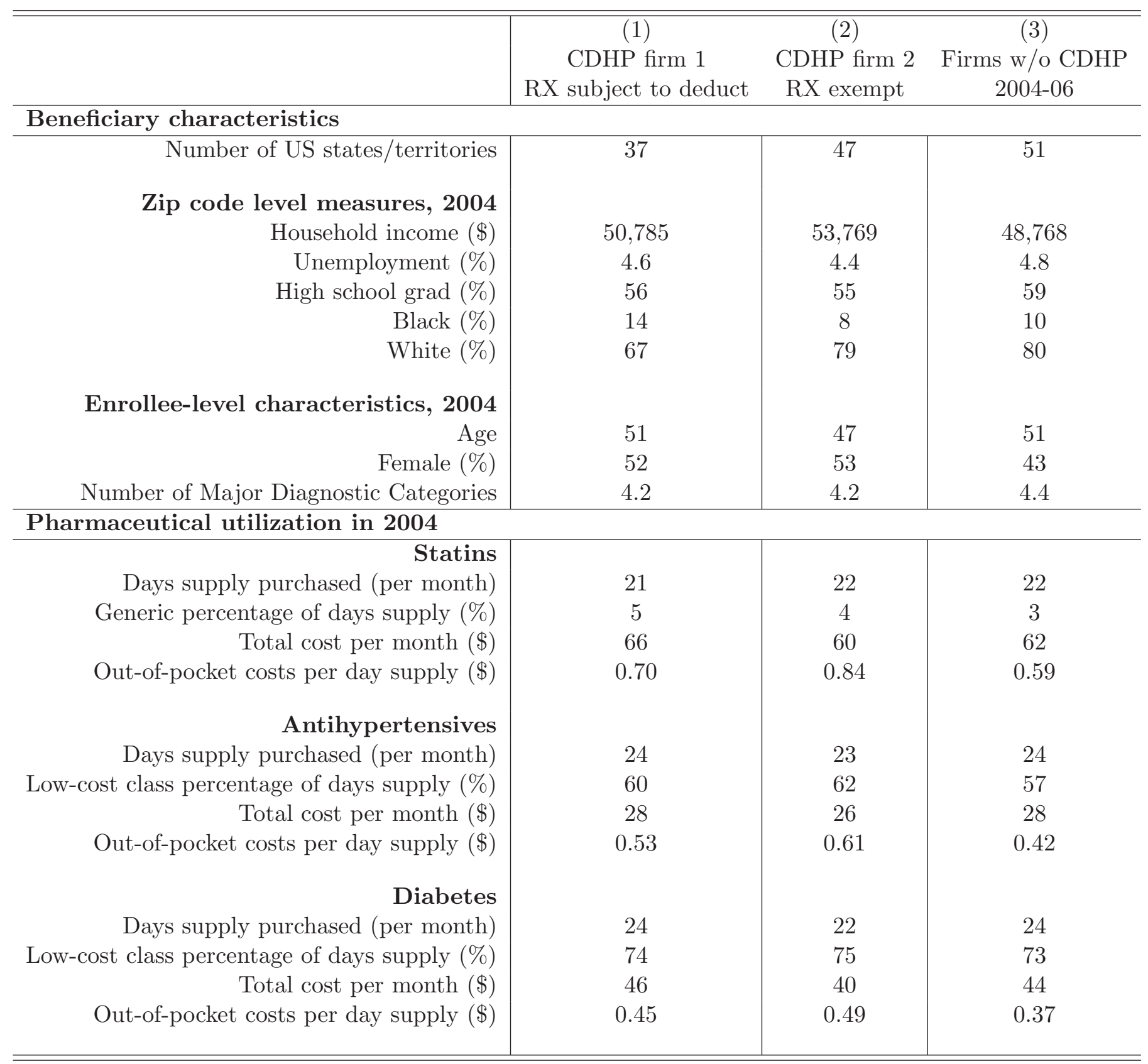

Note: Enrollee-level characteristics for CDHP firm 1 (other than number of Major Diagnostic Categories) only available for beneficiaries continuously enrolled from 2004-2006. 
Table 4: Year 1 effects for CDHP firm 1, RX subject to deductible

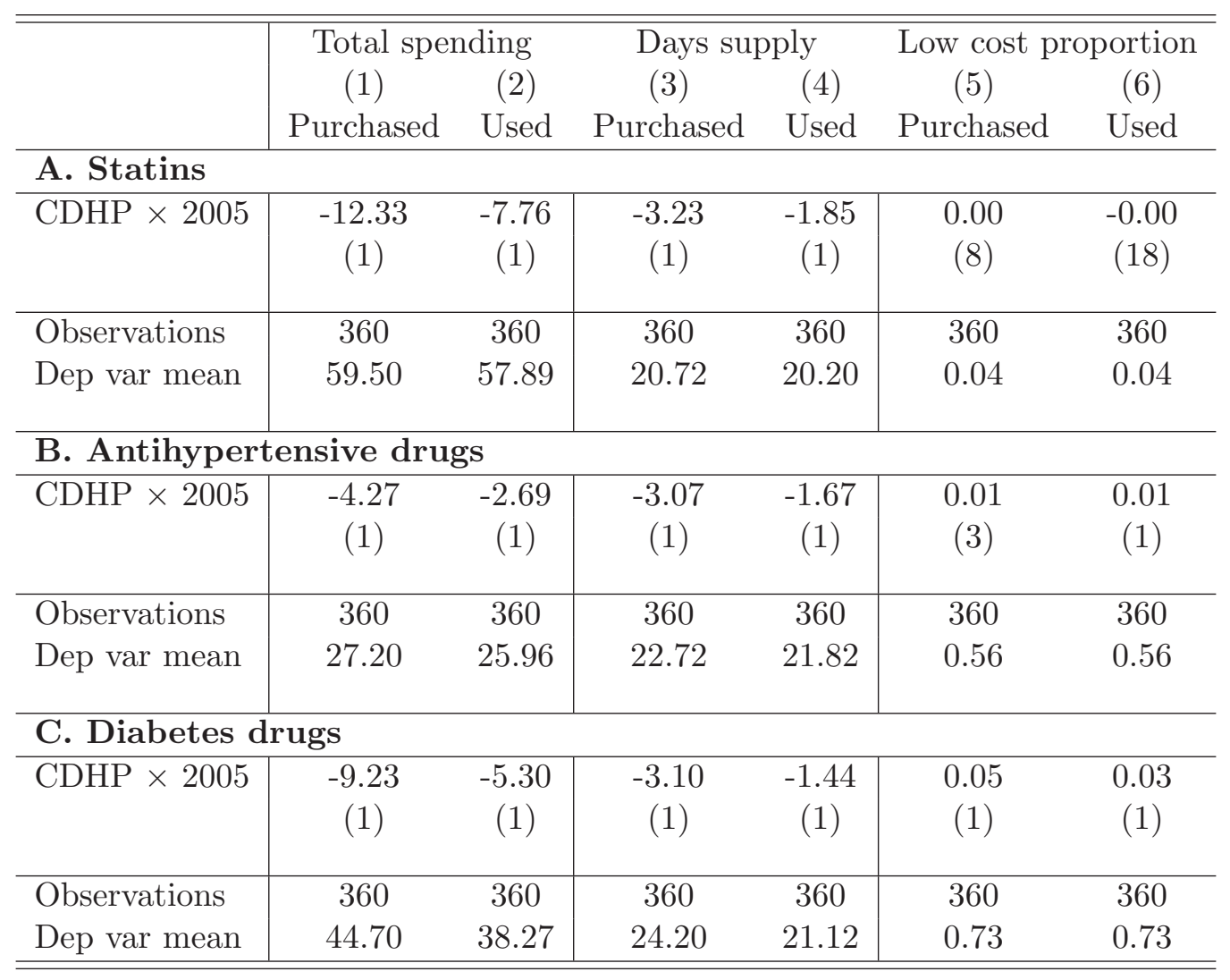

Data include firm-month observations from July 2004-December 2005. Ranking of effect out of 20 from permutation tests in parentheses. 
Table 5: Year 1 effects for CDHP firm 2, RX exempt from deductible

\begin{tabular}{|c|c|c|c|c|c|c|}
\hline & \multicolumn{2}{|c|}{ Total spending } & \multicolumn{2}{|c|}{ Days supply } & \multicolumn{2}{|c|}{ Low cost proportion } \\
\hline & (1) & $(2)$ & $(3)$ & $(4)$ & $(5)$ & $(6)$ \\
\hline & Purchased & Used & Purchased & Used & Purchased & Used \\
\hline \multicolumn{7}{|l|}{ A. Statins } \\
\hline $\mathrm{CDHP} \times 2005$ & $\begin{array}{c}-2.17 \\
(3)\end{array}$ & $\begin{array}{c}-1.30 \\
(6)\end{array}$ & $\begin{array}{c}-0.93 \\
(3)\end{array}$ & $\begin{array}{c}-0.62 \\
(3)\end{array}$ & $\begin{array}{c}0.00 \\
(5)\end{array}$ & $\begin{array}{c}0.00 \\
(5)\end{array}$ \\
\hline Observations & 360 & 360 & 360 & 360 & 360 & 360 \\
\hline Dep var mean & 59.52 & 57.93 & 20.81 & 20.29 & 0.04 & 0.04 \\
\hline \multicolumn{7}{|c|}{ B. Antihypertensive drugs } \\
\hline $\mathrm{CDHP} \times 2005$ & $\begin{array}{c}-0.65 \\
(5)\end{array}$ & $\begin{array}{c}-0.51 \\
(6)\end{array}$ & $\begin{array}{c}-0.82 \\
(1)\end{array}$ & $\begin{array}{c}-0.63 \\
(2)\end{array}$ & $\begin{array}{c}0.00 \\
(8)\end{array}$ & $\begin{array}{c}0.00 \\
(7)\end{array}$ \\
\hline Observations & 360 & 360 & 360 & 360 & 360 & 360 \\
\hline Dep var mean & 27.25 & 26.02 & 22.77 & 21.89 & 0.56 & 0.56 \\
\hline \multicolumn{7}{|c|}{ C. Diabetes drugs } \\
\hline $\mathrm{CDHP} \times 2005$ & $\begin{array}{c}-2.15 \\
(4)\end{array}$ & $\begin{array}{c}-0.98 \\
(2)\end{array}$ & $\begin{array}{c}-1.53 \\
(1)\end{array}$ & $\begin{array}{c}-0.87 \\
(1)\end{array}$ & $\begin{array}{c}-0.02 \\
(20)\end{array}$ & $\begin{array}{c}-0.01 \\
(20)\end{array}$ \\
\hline Observations & 360 & 360 & 360 & 360 & 360 & 360 \\
\hline Dep var mean & 44.68 & 38.22 & 24.17 & 21.09 & 0.73 & 0.73 \\
\hline
\end{tabular}

Data include firm-month observations from July 2004-December 2005. Ranking of effect out of 20 from permutation tests in parentheses. 


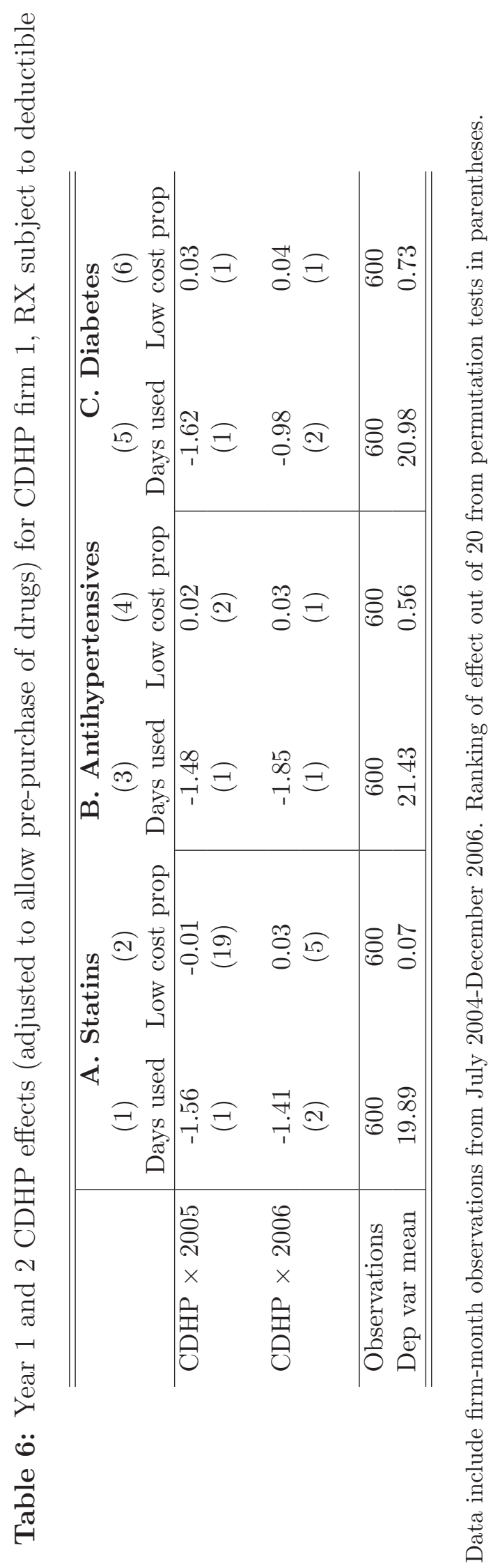







Table 8: Bimonthly CDHP effects on day supply in 2005 for CDHP firm 1, RX subject to deductible

\begin{tabular}{|c|c|c|c|c|c|c|}
\hline & \multicolumn{2}{|c|}{ Statins } & \multicolumn{2}{|c|}{ Antihypertensives } & \multicolumn{2}{|c|}{ Diabetes } \\
\hline & (1) & $(2)$ & $(3)$ & $(4)$ & $(5)$ & $(6)$ \\
\hline & Purchased & Used & Purchased & Used & Purchased & Used \\
\hline \multirow[t]{2}{*}{ Two months prior } & 4.24 & 2.03 & 2.27 & 0.53 & 0.95 & 1.01 \\
\hline & $(1)$ & $(1)$ & $(1)$ & $(1)$ & $(2)$ & (1) \\
\hline \multirow{2}{*}{ Months post 1-2 } & -4.23 & -1.10 & -5.88 & -2.04 & -5.80 & -1.62 \\
\hline & $(2)$ & $(2)$ & $(1)$ & $(1)$ & $(1)$ & $(1)$ \\
\hline \multirow[t]{2}{*}{ Months post $3-4$} & -2.68 & -2.18 & -1.92 & -2.11 & -3.83 & -1.80 \\
\hline & $(1)$ & $(1)$ & $(1)$ & $(1)$ & $(1)$ & $(1)$ \\
\hline \multirow[t]{2}{*}{ Months post 5-6 } & -2.06 & -1.64 & -1.68 & -1.17 & -2.77 & -1.17 \\
\hline & $(1)$ & $(2)$ & $(1)$ & $(2)$ & $(1)$ & $(1)$ \\
\hline \multirow[t]{2}{*}{ Months post $7-8$} & -1.51 & -1.52 & -1.90 & -1.19 & -1.51 & -0.83 \\
\hline & $(1)$ & $(1)$ & $(1)$ & $(1)$ & $(3)$ & $(2)$ \\
\hline \multirow[t]{2}{*}{ Months post $9-10$} & -1.11 & -0.90 & -2.61 & -1.64 & -3.35 & -1.26 \\
\hline & $(2)$ & $(3)$ & $(1)$ & (1) & $(2)$ & $(1)$ \\
\hline \multirow[t]{2}{*}{ Months post $11-12$} & 0.71 & 0.32 & 0.12 & -0.78 & 0.59 & 0.04 \\
\hline & (19) & $(11)$ & $(12)$ & $(3)$ & $(17)$ & $(11)$ \\
\hline Observations & 360 & 360 & 360 & 360 & 360 & 360 \\
\hline Dep var mean & 20.72 & 20.20 & 22.72 & 21.82 & 24.20 & 21.12 \\
\hline
\end{tabular}

Data include firm-month observations from July 2004-December 2005. Ranking of effect out of 20 from permutation tests in parentheses. 
Table 9: Decomposition of CDHP firm 1 effects: changes in expenditures in Year 1 relative to no behavior change

\begin{tabular}{c|ccc}
\hline & $\begin{array}{c}(1) \\
\text { Statins }\end{array}$ & $\begin{array}{c}(2) \\
\text { Antihypertensives }\end{array}$ & $\begin{array}{c}(3) \\
\text { Diabetes }\end{array}$ \\
\hline 1. Decomposition of changes in monthly out-of-pocket spending & & $10 \%$ \\
Timing of purchase as \% of total savings & $10 \%$ & $<1 \%$ & $58 \%$ \\
Reduction in utilization as \% of total savings & $90 \%$ & $93 \%$ & $33 \%$ \\
\hline Low cost drug use as \% of total savings & $0 \%$ & $7 \%$ & $-\$ 2.04$ \\
Total savings across margins (\$) & $-\$ 4.31$ & $-\$ 1.61$ & $15 \%$ \\
\hline As percentage of monthly OOP on drug class & $20 \%$ & $10 \%$ & $-3 \%$ \\
\hline 2. Decomposition of changes in monthly total spending & $-1 \%$ & $-2 \%$ & $66 \%$ \\
\hline Timing of purchase as \% of total savings & $101 \%$ & $95 \%$ & $37 \%$ \\
\hline Reduction in utilization as \% of total savings & $0 \%$ & $7 \%$ & $-\$ 5.64$ \\
Low cost drug use as \% of total savings & $-\$ 10.83$ & $-\$ 3.13$ & $10 \%$ \\
\hline As percentage of total monthly spending on drug class & $11 \%$ & $9 \%$ & \\
\hline
\end{tabular}


Figure A.1: Spending towards deductible and health reimbursement account (HRA) balances by month for enrollees in sample, 2005

(a) HRA balance by month

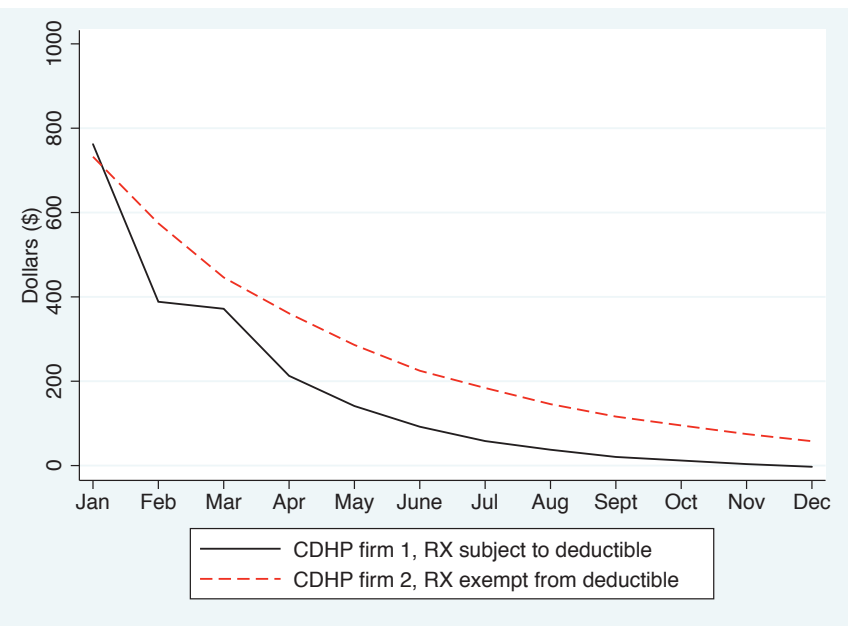

(c) Percentage of enrollees reaching deductible

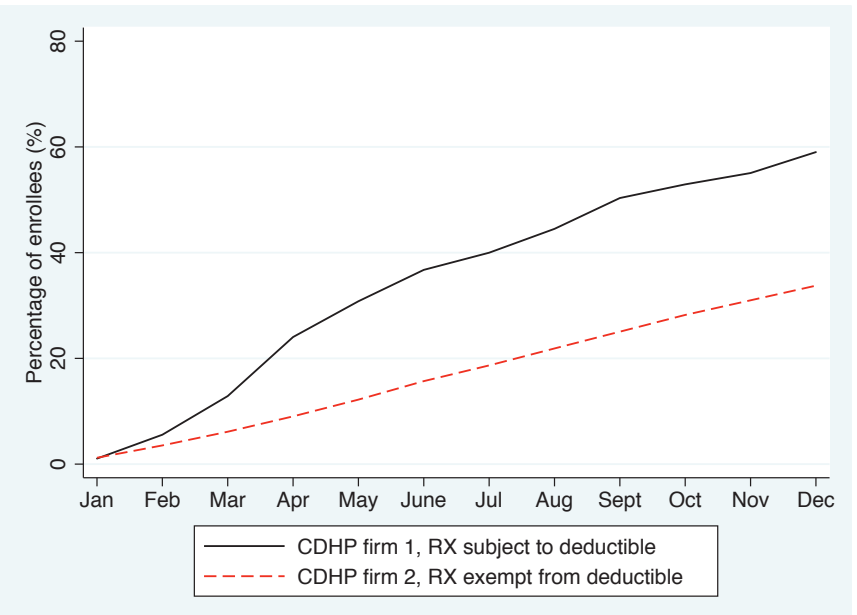

(b) Percentage of enrollees with zero HRA balance

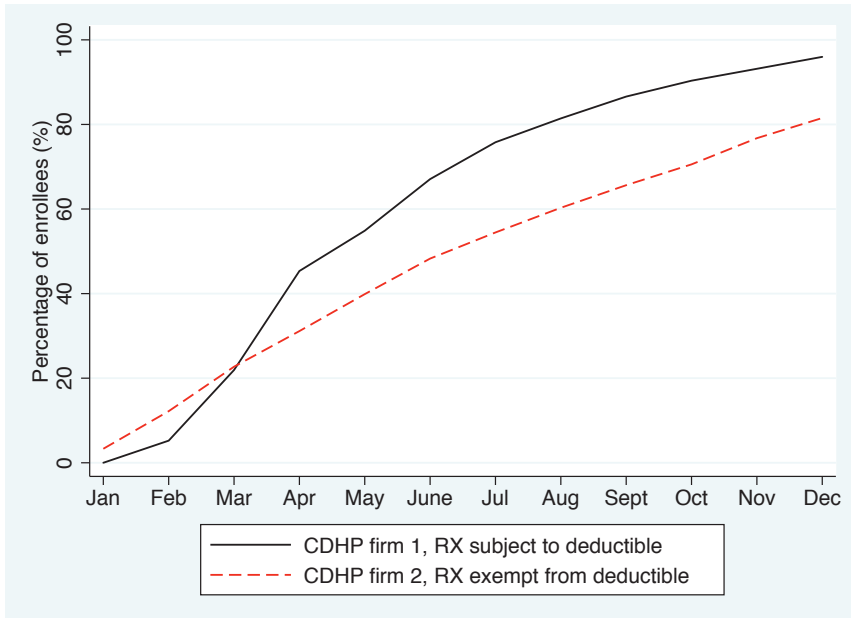

(d) Percentage of enrollees with zero HRA balance, but have not reached deductible

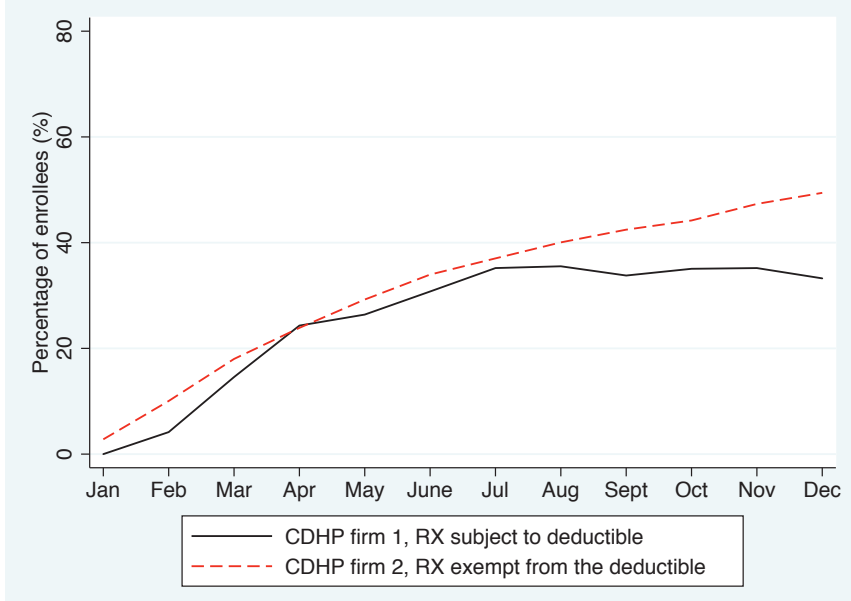


Figure A.2: Days supply purchased, relative to reaching deductible in 2005

(a) Statins

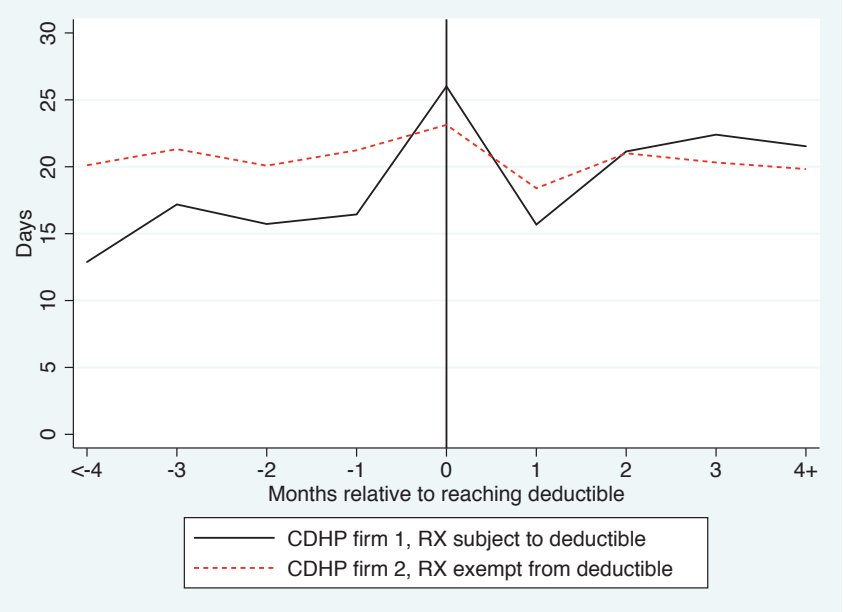

(c) Diabetes drugs

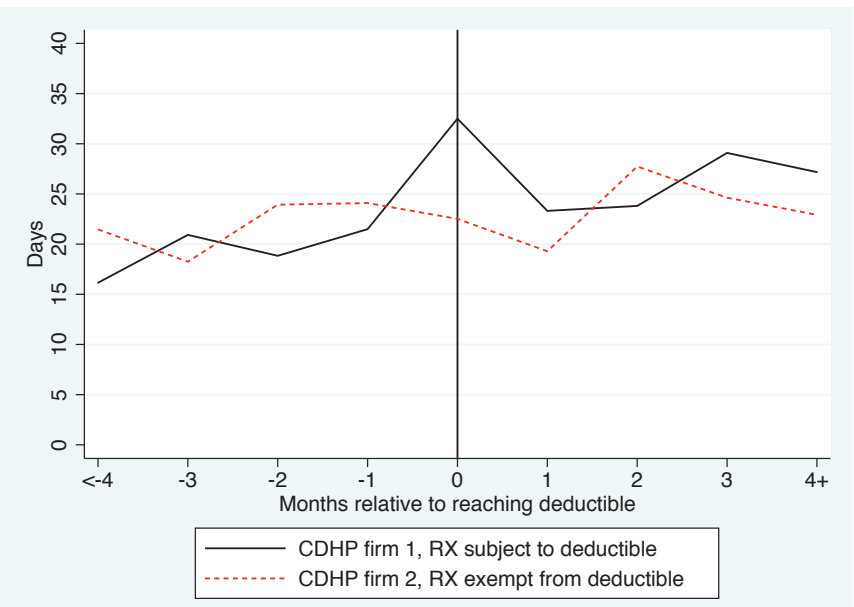

(b) Antihypertensives

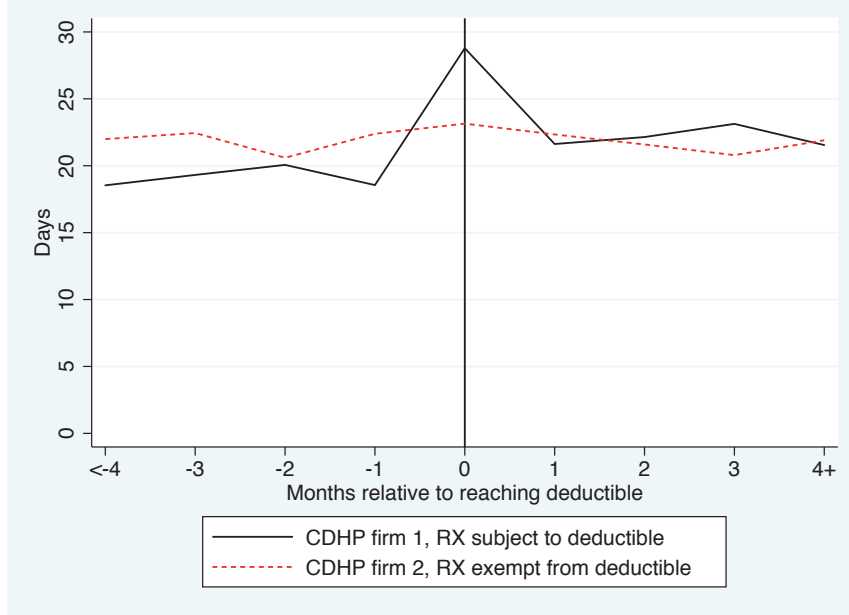


Table A.1: Bimonthly CDHP effects on day supply in 2005 for CDHP firm 2, RX exempt from deductible

\begin{tabular}{|c|c|c|c|c|c|c|}
\hline & \multicolumn{2}{|c|}{ Statins } & \multicolumn{2}{|c|}{ Antihypertensives } & \multicolumn{2}{|c|}{ Diabetes } \\
\hline & (1) & $(2)$ & $(3)$ & $(4)$ & (5) & $(6)$ \\
\hline & Purchased & Used & Purchased & Used & Purchased & Used \\
\hline 2 months prior & $\begin{array}{c}0.47 \\
(5)\end{array}$ & $\begin{array}{c}0.25 \\
(8)\end{array}$ & $\begin{array}{c}1.06 \\
(2)\end{array}$ & $\begin{array}{c}0.29 \\
(4)\end{array}$ & $\begin{array}{c}0.25 \\
(6)\end{array}$ & $\begin{array}{c}0.37 \\
(4)\end{array}$ \\
\hline Months post 1-2 & $\begin{array}{c}-1.19 \\
(3)\end{array}$ & $\begin{array}{c}-0.44 \\
(4)\end{array}$ & $\begin{array}{c}-0.77 \\
(5)\end{array}$ & $\begin{array}{c}-0.12 \\
(7)\end{array}$ & $\begin{array}{c}-0.68 \\
(5)\end{array}$ & $\begin{array}{l}0.06 \\
(10)\end{array}$ \\
\hline Months post $3-4$ & $\begin{array}{c}-0.77 \\
(3)\end{array}$ & $\begin{array}{c}-0.64 \\
(3)\end{array}$ & $\begin{array}{c}-0.10 \\
(10)\end{array}$ & $\begin{array}{c}-0.61 \\
(2)\end{array}$ & $\begin{array}{c}-0.50 \\
(3)\end{array}$ & $\begin{array}{c}-0.48 \\
(2)\end{array}$ \\
\hline Months post 5-6 & $\begin{array}{c}-0.75 \\
(5)\end{array}$ & $\begin{array}{c}-0.57 \\
(3)\end{array}$ & $\begin{array}{c}-0.58 \\
(4)\end{array}$ & $\begin{array}{c}-0.64 \\
(2)\end{array}$ & $\begin{array}{c}-2.47 \\
(1)\end{array}$ & $\begin{array}{c}-0.94 \\
(1)\end{array}$ \\
\hline Months post $7-8$ & $\begin{array}{c}-0.92 \\
(3)\end{array}$ & $\begin{array}{c}-0.64 \\
(3)\end{array}$ & $\begin{array}{c}-0.47 \\
(7)\end{array}$ & $\begin{array}{c}-0.70 \\
(3)\end{array}$ & $\begin{array}{c}-1.10 \\
(6)\end{array}$ & $\begin{array}{c}-0.72 \\
(2)\end{array}$ \\
\hline Months post $9-10$ & $\begin{array}{c}-0.49 \\
(6)\end{array}$ & $\begin{array}{c}-0.43 \\
(4)\end{array}$ & $\begin{array}{c}-1.23 \\
(2)\end{array}$ & $\begin{array}{c}-0.52 \\
(3)\end{array}$ & $\begin{array}{c}-2.10 \\
(2)\end{array}$ & $\begin{array}{c}-1.10 \\
(1)\end{array}$ \\
\hline Months post $11-12$ & $\begin{array}{c}-0.53 \\
(5)\end{array}$ & $\begin{array}{c}-0.48 \\
(4)\end{array}$ & $\begin{array}{l}0.34 \\
(16) \\
\end{array}$ & $\begin{array}{c}-0.63 \\
(4)\end{array}$ & $\begin{array}{c}-1.84 \\
(2)\end{array}$ & $\begin{array}{c}-1.29 \\
(1)\end{array}$ \\
\hline Observations & 360.00 & 360.00 & 360.00 & 360.00 & 360.00 & 360.00 \\
\hline Dep var mean & 20.81 & 20.29 & 22.77 & 21.88 & 24.17 & 21.09 \\
\hline
\end{tabular}

Data include firm-month observations from July 2004-December 2005. Ranking of effect out of 20 from permutation tests in parentheses. 
Table A.2: Characteristics of plan enrollees using drug classes in 2004 by length of enrollment

\begin{tabular}{|c|c|c|c|}
\hline & $\begin{array}{c}(1) \\
\text { Used classes } 2004 \\
\text { no continuous } \\
\text { enroll 2005-2006 }\end{array}$ & $\begin{array}{c}(2) \\
\text { Used classes 2004, } \\
\text { enrolled } \\
2005-2006\end{array}$ & $\begin{array}{c}(3) \\
\text { P-value } \\
\text { of diff }\end{array}$ \\
\hline \multicolumn{4}{|c|}{ CDHP firm 1: RX subject to deductible } \\
\hline $\begin{array}{l}\text { Number of major diagnostic categories } \\
\text { Zip code level measures }\end{array}$ & 3.7 & 4.4 & 0.000 \\
\hline Median HH income $(\$)$ & 49,424 & 50,539 & 0.180 \\
\hline Black (\%) & 14 & 14 & 0.974 \\
\hline White (\%) & 69 & 68 & 0.159 \\
\hline Unemployed \% & 5 & 5 & 0.517 \\
\hline High school grad (\%) & 57 & 56 & 0.028 \\
\hline College graduate (\%) & 27 & 27 & 0.412 \\
\hline Number of enrollees & 813 & 984 & \\
\hline \multicolumn{4}{|c|}{ CDHP firm 2: RX exempt from deductible } \\
\hline $\begin{array}{l}\text { Number of major diagnostic categories } \\
\text { Zip code level measures }\end{array}$ & 3.7 & 4.2 & 0.000 \\
\hline Median HH income $(\$)$ & 52,532 & 53,742 & 0.028 \\
\hline Black $(\%)$ & 10 & 9 & 0.118 \\
\hline White $(\%)$ & 75 & 79 & 0.000 \\
\hline Unemployed (\%) & 5 & 4 & 0.635 \\
\hline High school grad (\%) & 55 & 55 & 0.556 \\
\hline College grad $(\%)$ & 31 & 31 & 0.453 \\
\hline Number of enrollees & 1,925 & 2,619 & \\
\hline \multicolumn{4}{|c|}{ Control firms only offering conventional plans } \\
\hline $\begin{array}{l}\text { Number of major diagnostic categories } \\
\text { Zip code level measures }\end{array}$ & 3.9 & 4.5 & 0.000 \\
\hline Median HH income $(\$)$ & 48,894 & 48,898 & 0.963 \\
\hline Black $(\%)$ & 9 & 10 & 0.037 \\
\hline White (\%) & 78 & 81 & 0.000 \\
\hline Unemployed (\%) & 5 & 5 & 0.000 \\
\hline High school grad (\%) & 58 & 59 & 0.000 \\
\hline College grad (\%) & 25 & 25 & 0.000 \\
\hline Number of enrollees & 68,198 & 190,280 & \\
\hline
\end{tabular}


Table A.3: Retention rates: percentage of sample using drug class in year that is continuously enrolled in plan in subsequent year

\begin{tabular}{l|ccc}
\hline \hline & $(1)$ & $(2)$ & $(3)$ \\
& 2004 & 2005 & 2006 \\
\hline CDHP firm 1: & RX subject to deductible \\
\hline Statins & $62 \%$ & $67 \%$ & $61 \%$ \\
Antihypertensives & $61 \%$ & $66 \%$ & $59 \%$ \\
Diabetes & $58 \%$ & $66 \%$ & $55 \%$ \\
\hline CDHP firm 2: RX exempt from deductible \\
\hline Statins & $69 \%$ & $55 \%$ & $71 \%$ \\
Antihypertensives & $68 \%$ & $55 \%$ & $70 \%$ \\
Diabetes & $67 \%$ & $54 \%$ & $70 \%$ \\
\hline Control firms only offering conventional plans \\
\hline Statins & $77 \%$ & $77 \%$ & $76 \%$ \\
Antihypertensives & $76 \%$ & $77 \%$ & $75 \%$ \\
Diabetes & $75 \%$ & $75 \%$ & $74 \%$ \\
\hline
\end{tabular}


Table A.4: Sample sizes and retention rates by period with drug use in 2004

\begin{tabular}{l|cccc}
\hline \hline & \multicolumn{2}{c}{ Sample size } & \multicolumn{2}{c}{ Retention rate for year 1 sample } \\
& Jan-Sept 2004 Jul-Sept 2004 & Jan-Sept 2004 & Jul-Sept 2004 \\
\hline CDHP firm 1: RX subject to deductible & & \\
\hline Statin & 1,118 & 866 & $62 \%$ & $67 \%$ \\
Antihypertensives & 1,195 & 944 & $61 \%$ & $67 \%$ \\
Diabetes & 685 & 533 & $58 \%$ & $66 \%$ \\
\hline \multicolumn{7}{l}{ Control firms only offering conventional plans } \\
\hline Statin & 177,695 & 139,984 & $77 \%$ & $81 \%$ \\
Antihypertensives & 163,444 & 132,172 & $76 \%$ & $80 \%$ \\
Diabetes & 62,344 & 50,710 & $75 \%$ & $79 \%$ \\
\hline \hline
\end{tabular}


Table A.5: Year 1 effects for CDHP firm 1, enrollees using drug in July- Sept 2004

\begin{tabular}{|c|c|c|c|c|c|c|}
\hline & \multicolumn{2}{|c|}{ Total spending } & \multicolumn{2}{|c|}{ Days supply } & \multicolumn{2}{|c|}{ Low cost proportion } \\
\hline & $(1)$ & $(2)$ & $(3)$ & $(4)$ & $(5)$ & $(6)$ \\
\hline & Purchased & Used & Purchased & Used & Purchased & Used \\
\hline \multicolumn{7}{|l|}{ A. Statins } \\
\hline $\mathrm{CDHP} \times 2005$ & $\begin{array}{c}-12.18 \\
(1)\end{array}$ & $\begin{array}{c}-8.88 \\
(1)\end{array}$ & $\begin{array}{c}-2.91 \\
(2)\end{array}$ & $\begin{array}{c}-2.04 \\
(1)\end{array}$ & $\begin{array}{c}0.00 \\
(4)\end{array}$ & $\begin{array}{c}-0.00 \\
(12)\end{array}$ \\
\hline Observations & 360 & 360 & 360 & 360 & 360 & 360 \\
\hline Dep var mean & 76.29 & 65.19 & 26.91 & 22.80 & 0.03 & 0.03 \\
\hline \multicolumn{7}{|c|}{ B. Antihypertensive drugs } \\
\hline $\mathrm{CDHP} \times 2005$ & $\begin{array}{c}-4.22 \\
(1)\end{array}$ & $\begin{array}{c}-2.85 \\
(1)\end{array}$ & $\begin{array}{c}-2.90 \\
(1)\end{array}$ & $\begin{array}{c}-1.75 \\
(1)\end{array}$ & $\begin{array}{c}0.01 \\
(3)\end{array}$ & $\begin{array}{c}0.01 \\
(2)\end{array}$ \\
\hline Observations & 360 & 360 & 360 & 360 & 360 & 360 \\
\hline Dep var mean & 30.01 & 28.46 & 25.05 & 23.91 & 0.56 & 0.56 \\
\hline \multicolumn{7}{|c|}{ C. Diabetes drugs } \\
\hline $\mathrm{CDHP} \times 2005$ & $\begin{array}{c}-9.30 \\
(1)\end{array}$ & $\begin{array}{c}-6.04 \\
(1)\end{array}$ & $\begin{array}{c}-2.78 \\
(1)\end{array}$ & $\begin{array}{c}-1.55 \\
(1)\end{array}$ & $\begin{array}{c}0.06 \\
(1)\end{array}$ & $\begin{array}{c}0.04 \\
(1)\end{array}$ \\
\hline Observations & 360 & 360 & 360 & 360 & 360 & 360 \\
\hline Dep var mean & 49.34 & 42.01 & 26.68 & 23.15 & 0.73 & 0.73 \\
\hline
\end{tabular}

Data include firm-month observations from July 2004-December 2005. Ranking of effect out of 20 from permutation tests in parentheses. 
Table A.6: Unweighted and weighted sample characteristics for control firms relative to CDHP firm 1

\begin{tabular}{|c|c|c|c|c|c|}
\hline & $\begin{array}{c}\text { CDHP firm } 1 \\
\text { Mean }\end{array}$ & $\begin{array}{l}19 \text { contr } \\
\text { Mean }\end{array}$ & $\begin{array}{l}\text { firms, unweighted } \\
\# \text { of std diff }<0.25\end{array}$ & $\begin{array}{l}19 \text { cont } \\
\text { Mean }\end{array}$ & $\begin{array}{l}\text { rol firms, weighted } \\
\# \text { of std } \operatorname{diff}<0.25\end{array}$ \\
\hline \multicolumn{6}{|l|}{ A. Statins } \\
\hline Median household income $(\$)$ & 50,820 & 50,410 & 9 & 49,468 & 16 \\
\hline Unemployment (\%) & 4.5 & 4.8 & 13 & 4.7 & 16 \\
\hline High school & 56 & 58 & 6 & 56 & 19 \\
\hline College & 27 & 26 & 7 & 26 & 17 \\
\hline Black & 13 & 9 & 8 & 15 & 16 \\
\hline Hispanic & 13 & 7 & 6 & 13 & 16 \\
\hline White & 68 & 79 & 5 & 67 & 18 \\
\hline \multicolumn{6}{|l|}{ B. Antihypertensive drugs } \\
\hline Median household income $(\$)$ & 50,492 & 48,479 & 10 & 49,091 & 16 \\
\hline Unemployment (\%) & 4.6 & 5.0 & 14 & 4.8 & 16 \\
\hline High school & 56 & 59 & 6 & 56 & 18 \\
\hline College & 27 & 24 & 6 & 27 & 18 \\
\hline Black & 14 & 11 & 10 & 15 & 18 \\
\hline Hispanic & 12 & 8 & 8 & 14 & 16 \\
\hline White & 68 & 77 & 6 & 66 & 17 \\
\hline \multicolumn{6}{|l|}{ C. Diabetes } \\
\hline Median household income $(\$)$ & 50,334 & 46,622 & 9 & 48,665 & 15 \\
\hline Unemployment (\%) & 4.6 & 5.3 & 5 & 4.8 & 15 \\
\hline High school & 55 & 59 & 6 & 55 & 17 \\
\hline College & 28 & 22 & 7 & 27 & 16 \\
\hline Black & 14 & 12 & 10 & 16 & 14 \\
\hline Hispanic & 14 & 9 & 10 & 15 & 14 \\
\hline White & 66 & 74 & 7 & 62 & 15 \\
\hline
\end{tabular}


Table A.7: Year 1 effects for CDHP firm 1, inverse probability weighted control sample

\begin{tabular}{|c|c|c|c|c|c|c|}
\hline & \multicolumn{2}{|c|}{ Total spending } & \multicolumn{2}{|c|}{ Days supply } & \multicolumn{2}{|c|}{ Low cost proportion } \\
\hline & (1) & $(2)$ & $(3)$ & $(4)$ & (5) & $(6)$ \\
\hline & Purchased & Used & Purchased & Used & Purchased & Used \\
\hline \multicolumn{7}{|l|}{ A. Statins } \\
\hline $\mathrm{CDHP} \times 2005$ & $\begin{array}{c}-12.59 \\
(1)\end{array}$ & $\begin{array}{c}-7.87 \\
(1)\end{array}$ & $\begin{array}{c}-3.39 \\
(1)\end{array}$ & $\begin{array}{c}-1.93 \\
(1)\end{array}$ & $\begin{array}{c}0.01 \\
(6)\end{array}$ & $\begin{array}{c}-0.00 \\
(16)\end{array}$ \\
\hline Observations & 360 & 360 & 360 & 360 & 360 & 360 \\
\hline Dep var mean & 58.40 & 56.84 & 20.23 & 19.72 & 0.04 & 0.04 \\
\hline \multicolumn{7}{|c|}{ B. Antihypertensive drugs } \\
\hline $\mathrm{CDHP} \times 2005$ & $\begin{array}{c}-4.29 \\
(1)\end{array}$ & $\begin{array}{c}-2.53 \\
(1)\end{array}$ & $\begin{array}{c}-3.16 \\
(1)\end{array}$ & $\begin{array}{c}-1.57 \\
(2)\end{array}$ & $\begin{array}{c}0.01 \\
(5)\end{array}$ & $\begin{array}{c}0.01 \\
(5)\end{array}$ \\
\hline Observations & 360 & 360 & 360 & 360 & 360 & 360 \\
\hline Dep var mean & 26.63 & 25.37 & 22.45 & 21.56 & 0.56 & 0.57 \\
\hline \multicolumn{7}{|c|}{ C. Diabetes drugs } \\
\hline $\mathrm{CDHP} \times 2005$ & $\begin{array}{c}-8.02 \\
(1)\end{array}$ & $\begin{array}{c}-4.79 \\
(3)\end{array}$ & $\begin{array}{c}-2.97 \\
(1)\end{array}$ & $\begin{array}{c}-1.45 \\
(2)\end{array}$ & $\begin{array}{c}0.05 \\
(1)\end{array}$ & $\begin{array}{c}0.03 \\
(3)\end{array}$ \\
\hline Observations & 360 & 360 & 360 & 360 & 360 & 360 \\
\hline Dep var mean & 42.45 & 36.84 & 23.87 & 20.99 & 0.73 & 0.74 \\
\hline
\end{tabular}

Data include firm-month observations from July 2004-December 2005. Ranking of effect out of 20 from permutation tests in parentheses. 
Table A.8: Unweighted and weighted sample characteristics for control firms relative to CDHP firm 2

\begin{tabular}{|c|c|c|c|c|c|}
\hline & $\begin{array}{c}\text { CDHP firm } 2 \\
\text { Mean }\end{array}$ & \multicolumn{2}{|c|}{$\begin{array}{l}19 \text { control firms, unweighted } \\
\text { Mean } \quad \# \text { of std diff }<0.25\end{array}$} & \multicolumn{2}{|c|}{$\begin{array}{l}19 \text { control firms, weighted } \\
\text { Mean \# of std diff }<0.25\end{array}$} \\
\hline \multicolumn{6}{|l|}{ A. Statins } \\
\hline Median household income $(\$)$ & 55,544 & 50,410 & 6 & 56,547 & 17 \\
\hline Unemployment (\%) & 4.2 & 4.8 & 13 & 4.3 & 18 \\
\hline High school & 55 & 58 & 6 & 53 & 15 \\
\hline College & 32 & 26 & 5 & 34 & 15 \\
\hline Black & 8 & 9 & 15 & 8 & 18 \\
\hline Hispanic & 7 & 7 & 6 & 8 & 15 \\
\hline White & 80 & 79 & 9 & 77 & 16 \\
\hline \multicolumn{6}{|l|}{ B. Antihypertensive drugs } \\
\hline Median household income $(\$)$ & 52,719 & 48,479 & 9 & 52,527 & 17 \\
\hline Unemployment (\%) & 4.5 & 5.0 & 14 & 4.6 & 18 \\
\hline High school & 56 & 59 & 7 & 55 & 16 \\
\hline College & 30 & 24 & 5 & 32 & 15 \\
\hline Black & 9 & 11 & 14 & 9 & 17 \\
\hline Hispanic & 8 & 8 & 5 & 10 & 16 \\
\hline White & 78 & 77 & 9 & 76 & 16 \\
\hline \multicolumn{6}{|l|}{ C. Diabetes } \\
\hline Median household income $(\$)$ & 49,668 & 46,622 & 9 & 49,869 & 17 \\
\hline Unemployment (\%) & 4.8 & 5.3 & 15 & 4.9 & 18 \\
\hline High school & 57 & 59 & 8 & 55 & 15 \\
\hline College & 27 & 22 & 7 & 30 & 15 \\
\hline Black & 11 & 12 & 14 & 11 & 15 \\
\hline Hispanic & 9 & 9 & 5 & 12 & 15 \\
\hline White & 75 & 74 & 6 & 69 & 16 \\
\hline
\end{tabular}


Table A.9: Year 1 effects for CDHP firm 2, inverse probability weighted control sample

\begin{tabular}{|c|c|c|c|c|c|c|}
\hline & \multicolumn{2}{|c|}{ Total spending } & \multicolumn{2}{|c|}{ Days supply } & \multicolumn{2}{|c|}{ Low cost proportion } \\
\hline & $(1)$ & $(2)$ & $(3)$ & $(4)$ & $(5)$ & (6) \\
\hline & Purchased & Used & Purchased & Used & Purchased & Used \\
\hline \multicolumn{7}{|l|}{ A. Statins } \\
\hline $\mathrm{CDHP} \times 2005$ & $\begin{array}{c}-1.97 \\
(5)\end{array}$ & $\begin{array}{c}-1.65 \\
(7)\end{array}$ & $\begin{array}{c}-0.97 \\
(4)\end{array}$ & $\begin{array}{c}-0.79 \\
(4)\end{array}$ & $\begin{array}{c}0.01 \\
(6)\end{array}$ & $\begin{array}{c}0.01 \\
(5)\end{array}$ \\
\hline Observations & 360 & 360 & 360 & 360 & 360 & 360 \\
\hline Dep var mean & 60.97 & 59.06 & 21.31 & 20.68 & 0.04 & 0.04 \\
\hline \multicolumn{7}{|c|}{ B. Antihypertensive drugs } \\
\hline $\mathrm{CDHP} \times 2005$ & $\begin{array}{c}-1.01 \\
(4)\end{array}$ & $\begin{array}{c}-0.71 \\
(4)\end{array}$ & $\begin{array}{c}-1.20 \\
(1)\end{array}$ & $\begin{array}{c}-0.79 \\
(2)\end{array}$ & $\begin{array}{c}0.00 \\
(7)\end{array}$ & $\begin{array}{c}0.00 \\
(8)\end{array}$ \\
\hline Observations & 360 & 360 & 360 & 360 & 360 & 360 \\
\hline Dep var mean & 26.83 & 25.63 & 22.90 & 22.01 & 0.57 & 0.58 \\
\hline \multicolumn{7}{|c|}{ C. Diabetes drugs } \\
\hline $\mathrm{CDHP} \times 2005$ & $\begin{array}{c}-0.76 \\
(5)\end{array}$ & $\begin{array}{c}-0.64 \\
(7)\end{array}$ & $\begin{array}{c}-1.42 \\
(3)\end{array}$ & $\begin{array}{c}-1.13 \\
(2)\end{array}$ & $\begin{array}{c}-0.01 \\
(18)\end{array}$ & $\begin{array}{c}-0.02 \\
(18)\end{array}$ \\
\hline Observations & 360 & 360 & 360 & 360 & 360 & 360 \\
\hline Dep var mean & 43.07 & 37.26 & 24.42 & 21.44 & 0.74 & 0.74 \\
\hline
\end{tabular}

Data include firm-month observations from July 2004-December 2005. Ranking of effect out of 20 from permutation tests in parentheses. 
Appendix Table A.10. Drugs in sample

\begin{tabular}{|c|c|c|c|}
\hline Brand name & Generic name & Date available & Dates generic \\
\hline \multicolumn{4}{|l|}{ Statins } \\
\hline Advicor & lovastatin and niacin & Dec-01 & NA \\
\hline Altoprev & lovastatin extended release & June-02 & NA \\
\hline Caduet & amlodipine+atorvastatin & Jan-04 & NA \\
\hline Crestor & rosuvastatin & Aug-03 & NA \\
\hline Lescol & fluvastatin & Dec-93 & NA \\
\hline Lescol XL & fluvastatin extended-release & Oct-00 & NA \\
\hline Lipitor & atorvastatin & Dec-96 & NA \\
\hline Mevacor & lovastatin & Aug-87 & Dec-01 \\
\hline Pravachol & pravastatin & Oct-91 & Jun-06 \\
\hline Vytorin & ezetimibe/ simvastatin & Jun-04 & NA \\
\hline Zocor & simvastatin & Dec-91 & Jun-06 \\
\hline \multicolumn{4}{|c|}{ ACE Inhibitors+ ARBs } \\
\hline \multicolumn{4}{|l|}{ ACE Inhibitors } \\
\hline Lotensin & benazepril & 1991 & Feb-04 \\
\hline Lotensin HCT & benazepril HCT & 1992 & Feb-04 \\
\hline Lotrel & benazepril+amlodipine & 1995 & Apr-10 \\
\hline Capoten & captopril & 1981 & Mar-95 \\
\hline Capozide & captopril + HCT & 1984 & Oct-97 \\
\hline Vasotec & enalapril & 1985 & Aug-00 \\
\hline Vaseretic & enalapril+hct & 1986 & Sep-01 \\
\hline Lexxel & enalapril+felodipine & 1996 & NA \\
\hline Teczem & dilitiazem maleate+ enalapril & 1996 & NA \\
\hline Monopril & fosinopril & 1991 & Nov-03 \\
\hline Monopril HCT & fosinopril+HCT & 1994 & Dec-04 \\
\hline Zestril & lisinopril & 1988 & Jul-02 \\
\hline Prinivil & lisinopril & 1989 & Jul-02 \\
\hline Zestoretic & lisinopril+HCT & 1989 & Jul-02 \\
\hline Prinzide & lisinopril+ HCT & 1989 & Jul-02 \\
\hline Univasc & moexipril & 1995 & May-03 \\
\hline Uniretic & moexipril+ HCT & 1997 & May-07 \\
\hline Aceon & perindopril & 1993 & NA \\
\hline Accupril & quinapril & 1991 & Mar-04 \\
\hline Accuretic & quinapril+hct & 1999 & Mar-05 \\
\hline Altace & ramipril & 1991 & Oct-05 \\
\hline Mavik & trandolapril & 1996 & Jun-07 \\
\hline \multicolumn{4}{|l|}{$A R B S$} \\
\hline Atacand & candesartan & Jun-98 & NA \\
\hline Atacand HCT & candesartan+ HCT & Sep-00 & NA \\
\hline Teveten & eprosartan & Dec-97 & NA \\
\hline
\end{tabular}




\begin{tabular}{|c|c|c|c|}
\hline Teveten $\mathrm{HCT}$ & eprosartan + HCT & Nov-01 & NA \\
\hline Avapro & irbesartan & Sep-97 & NA \\
\hline Avalide & irbesartan +HCT & Sep-97 & NA \\
\hline Cozaar & losartan & Apr-95 & NA \\
\hline Hyzaar & losartan + HCT & Apr-95 & NA \\
\hline Benicar & olmesartan & Apr-02 & NA \\
\hline Benicar HCT & olmesartan + HCT & Jun-03 & NA \\
\hline Micardis & telmisartan & Nov-98 & NA \\
\hline Micardis HCT & telmisartan + HCT & Nov-00 & NA \\
\hline Diovan & valsartan & Dec-96 & NA \\
\hline Diovan HCT & valsartan + HCT & Mar-98 & NA \\
\hline \multicolumn{4}{|l|}{ Diabetes drugs } \\
\hline Glucophage & metformin hcl & Mar-95 & Jan-02 \\
\hline Glucophage XR & metformin ER & Oct-00 & Oct-03 \\
\hline Avandamet & $\begin{array}{l}\text { metformin } \mathrm{HCL}+ \\
\text { rosaglitazone }\end{array}$ & Oct-02 & NA \\
\hline Micronase & glyburide & May-84 & Dec-97 \\
\hline Glynase & micronized glyburide & Mar-92 & Dec-97 \\
\hline Glucovance & metformin+glyburide & Jul-00 & Feb-04 \\
\hline Metaglip & metformin+glipizide & Oct-02 & Dec-05 \\
\hline Glucotrol & glipizide & May-84 & May-94 \\
\hline Glucotrol XL & glipizide ER & Apr-94 & Sep-03 \\
\hline Amaryl & glimepiride & Nov-95 & Oct-05 \\
\hline Avandaryl & $\begin{array}{l}\text { glimepiride+rosiglitazone } \\
\text { maleate }\end{array}$ & Nov-05 & NA \\
\hline Avandia & rosaglitazone & May-99 & NA \\
\hline Actos & pioglitazone & Jul-99 & NA \\
\hline Actos Plus Met & metformin + pioglitazone & Aug-05 & NA \\
\hline Avandamet & metformin + rosiglitazone & Oct-02 & NA \\
\hline
\end{tabular}

Note: "NA" indicates generics became available either after the sample period (2004-2006) or are still not available . 